\title{
The list of asteroids perturbing the Mars orbit to be seen during future space missions ${ }^{\star}$
}

\author{
S. Mouret ${ }^{1,2}$, J. L. Simon ${ }^{2}$, F. Mignard ${ }^{3}$, and D. Hestroffer ${ }^{2}$ \\ 1 Lohrmann Observatory, Dresden Technical University, Institute for Planetary Geodesy, 01062 Dresden, Germany \\ e-mail: serge.mouret@tu-dresden.de \\ 2 IMCCE, UMR CNRS 8028, Paris observatory, 77 Av. Denfert-Rochereau, 75014 Paris, France \\ e-mail: [simon; hestroffer] @imcce.fr \\ 3 OCA/Cassiopée, UMR CNRS 6062, Observatory of the Côte d'Azur, Le Mont Gros, BP 4229, 06304 Nice Cedex 4, France \\ e-mail: francois.mignard@oca.eu
}

Received 17 September 2008 / Accepted 6 July 2009

ABSTRACT

\begin{abstract}
Context. Over the last decade, the positional observations of Mars have reached such an accuracy that the uncertainty of the asteroid masses has become the main cause of uncertainty in its ephemeris. Currently, only about 36 masses are estimated by direct measurements with a formal accuracy better than $10 \%$. However, the true errors are probably larger due to unaccounted systematic effects. Thus, asteroid masses are still a limitation in the accurate modeling of the perturbations on Mars. Nevertheless, two future space missions, Gaia and Dawn, could improve the situation by combining their results.

Aims. The main objective of this paper is to identify and provide a list of major perturbers of Mars which could bring significant disturbances over the next 50 years, having in perspective the expected contribution of Gaia to asteroid mass determination. It will also point out the asteroids whose mass only could be improved from ground-based observations - by direct measurements or size and shape derivation.

Methods. The selection procedure of Mars' perturbers includes analytical and numerical treatments. The analytical analysis is based on harmonic decomposition of the perturbations on the longitude and semi-major axis of Mars as a function of the mean longitude of the planet and the perturbing asteroid to the first order in asteroid mass. Regarding the numerical treatments, the first consists in selecting the potential perturbers, filtering them out with the cumulative deviations of Mars' path over the next 50 years. The second one uses the accumulation of the perturbations on the semi-major axis, eccentricity, and inclination of Mars due to each asteroid over the same period of time. Thus, a list of perturbers of Mars is derived from the number of selections by each method.

Results. 62 asteroids have been selected as the most perturbing - or potentially so - for the orbit of Mars, among which 32 were already listed by Williams in 1984, and all are in the list of 300 perturbing asteroids derived by the same author in about 1995 . More interestingly, 53 belong to the list of asteroids for which Gaia could give their mass with a relative precision better than $50 \%$ and 27 less than $10 \%$, a further indication of the importance of Gaia to contribute to improving Mars' ephemeris. Nevertheless, 7 of them will have a mass poorly estimated - with a relative error greater than $30 \%$ - and 9 without estimates at all. Therefore, ground-based observations may be useful to overcome these limitations.
\end{abstract}

Key words. celestial mechanics - minor planets - asteroids - ephemerides

\section{Introduction}

Today, the main factor limiting the precision of the ephemerides of Mars does not come from the intricacy of the dynamical modeling or the quality of the observational material, but rather from the lack of reliable masses of the largest asteroids. The masses of the three "bigs" - (1) Ceres (2) Pallas, and (4) Vesta - arrived at by Standish \& Hellings (1989) from the Viking lander spacecraft data left a post-fit accuracy of $7 \mathrm{~m}$ over the period from 1976 to 1980 and $12 \mathrm{~m}$ for 1980 to 1981 . Although the perturbations produced by these major asteroids are large enough to permit a rather accurate determination of their masses with precisions estimated to $0.2 \%$ for (1) Ceres, $1 \%$ for (2) Pallas, and $0.7 \%$ for (4) Vesta, which have been improved using the same method by Pitjeva (2005), Konopliv et al. (2006) and Fienga et al. (2008), the ephemeris solution would be constrained if these masses could be obtained from an independent source.

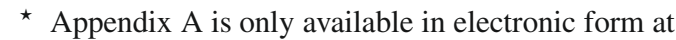
http://www. aanda.org
Given the interest of Mars for searches for signs of past biological activity, several missions have been launched and orbit the planet to monitor its surface, like Mars Global Surveyor (NASA-JPL) launched in November 1996 (Albee et al. 2001), Mars Odyssey in April 2001 (Saunders et al. 2004) or Mars Express (ESA) in June 2003 (Chicarro 2006). Even if their main objective is not the study of the dynamics of the planet, the spacecraft radio tracking allows us to obtain an accurate position of Mars. The level of accuracy is such that the perturbations of the asteroids are seen in the subsequent dynamical fit to these observations and a good knowledge of their masses would allow us to fully benefit from the accuracy of these observations to construct a stable and precise solution of the Martian orbit. More detail on this issue is given in Sect. 2.2.

To date we can rely on only 36 asteroid masses derived from direct measurements with a precision better than $10 \%$, while 54 reach the 50\% mark - statistics from Mouret (2007), Baer \& Chesley (2008), and Baer's database ${ }^{1}$. They have been obtained by analysing the gravitational pull on other 
Solar-System objects, mainly smaller asteroids, and in special cases Mars or a spacecraft (Near-Shoemaker). Our limited knowledge of asteroid masses becomes more obvious when we add that most precisions estimated from covariance matrix or post-fit residuals neglect the systematics resulting from the imperfection of the dynamical models used in the fitting. Regarding the very specific cases of binary asteroids, their mass is generally well-estimated, much less corrupted by systematic errors, but unfortunately, only a few of them are massive - fewer than ten have a mass greater than $10^{-13} M_{\odot}$.

Thus it is mandatory to obtain more stable solutions of the Martian orbit to (i) determine the asteroids capable of producing detectable perturbations of this planet; and (ii) see how their mass determinations could be improved. This may result either from well designed ground-based observations or by taking advantage of the capabilities of space missions like Gaia or Dawn, even though this is not their primary objectives. In the same spirit as the pioneering work of Williams (1984), we give a list of the most influential asteroids on the orbit of Mars over a short period of time, $\sim 50$ years. This small timespan is justified by the fact that even the short-term stability of the solution of Mars is not yet achieved (see Sect. 2.2). Thus, the case of resonant orbits between asteroids and Mars specified in Sect. 4 is not seen in this paper, since they imply long period perturbations. In addition, the list of perturbers is supplemented with the expected precisions on their masses from Gaia obtained from realistic simulated data (Mouret et al. 2008).

In Sect. 2.2, we give an overview of our current knowledge of the perturbers of Mars and explain the interest of future space missions in improving the ephemeris of Mars. Sections 4-6 give the description of the selection procedures and the resulting lists of asteroids. The results are summarised in Sect. 7 in the form of a ranking based on the number of times an asteroid was selected. This list is supplemented with the expected mass estimates from Gaia and compared to Williams' as well as the list of 300 asteroids for the DE405 ephemeris and 343 ones for DE414 and the next DE ephemerides (Folkner et al. 2008).

\section{State of the art}

\subsection{First discussions}

The first discussions on the perturbations of the Mars orbit by the asteroids appeared in papers by Bretagnon (1984) and Williams (1984). Bretagnon, in his planetary ephemerides, assessed the perturbations of the mean longitude of Mars by the three most massive asteroids - (1) Ceres, (2) Pallas, and (4) Vesta. The perturbations were expressed to the first and second order in asteroid mass, in the form of Fourier series with the longitudes of Mars and that of the minor planet as arguments, accounting for the associated amplitude and period. In his own investigation, Williams gave a list of massive asteroids in near mean-motion resonance with Mars likely to perturb its motion. But, more interestingly for this purpose, he also selected 36 asteroids based on the theoretical perturbations of Mars mean longitude over short and over intermediate periods ( $P>4$ years). As Williams said, this list can be viewed either as "an opportunity for measuring masses" or "a list of source noise for orbit determination". The importance of asteroid masses on the inner planet orbits (especially Mars) was taken seriously, and rightly, since he anticipated the future mass determinations for the three Bigs from the Viking Mars landers by Standish \& Hellings (1989). Later, Williams continued the study and an unpublished list of
300 asteroids $^{2}$ was derived in about 1995 to guide JPL's solar system integrations (Standish et al. 1995; Standish \& Williams 2009). They were obtained from more advanced work than its first study (Williams 1984), combining more accurate semianalytical theories with more terms for some asteroids and searching for resonances from an approximate semimajor axis-eccentricity function. Recently, Standish ${ }^{3}$ derived his own list considering the minor planets physical properties and by assessing the influence upon the Mars orbit from numerical integrations. This increased the content from 300 perturbing asteroids to 343 .

\subsection{Still great ignorance}

Up to now the list of Williams (1984) and, more particularly, its unpublished list of 300 asteroids have remained a reference to such an extent that these asteroids are included in the dynamical modeling for planetary ephemeris and also to assess the remaining uncertainty left by the insufficient knowledge of their masses. Standish \& Fienga (2002) extended the model with perturbing asteroids to the four inner planets. They set up Monte-Carlo simulations in order to compare the planetary solutions obtained from different sets of asteroid masses $-880 \mathrm{ob}-$ jects were considered - to evaluate the model accuracy. They arrived at the conclusion that the true uncertainties in the Earth and Mars ephemeris can be several kilometres over a period of about 10 years just from this effect.

Given our current ignorance on masses, one is reduced to handle the way of estimating them in order to model their perturbations on Mars. As to the JPL epehemeris whose aim is to get a reasonable short-period prediction which is important for NASA missions to Mars, a particular process was used. The asteroids considered in modeling Mars' ephemeris are split into two groups, the "major" and the "minor" according to their influence on Mars. In DE418, 12 asteroids among the "major" were empirically selected: the process consisted in searching which set of asteroids allowed to keep the residuals of the unfit range measurements in 2006 and 2007 small, the masses being estimated without constraints from the data through the end of $2005^{4}$. The other 56 "major" asteroids were held at assumed nominal values. As for the "minor" asteroids, their masses were estimated from three density classes, and a volume estimated. Improving the current data on the most important perturbers of Mars would allow to better model their perturbations but, also, those from the remaining smaller asteroids.

\section{3. ...but great expectations from space missions}

By foreseeing the possibility of measuring the masses of asteroids sufficiently perturbing Mars, the paper by Williams (1984) can also be viewed as a precursor for the detection of Mars perturbers. However, as it is difficult to pick out the perturbations from one asteroid among the large number of small perturbations on Mars, deriving masses by this method is limited to only the largest asteroids. Measuring asteroid masses appears as the current best solution to the problem of Mars ephemeris and several future space missions offer interesting perspectives in this regard.

\footnotetext{
${ }^{2}$ http://iau-comm4.jpl .nasa.gov/XSChap8.pdf

3 ftp://ssd.jpl.nasa.gov/pub/eph/planets/ioms/de421. iom.v1.pdf

4 ftp://ssd.jpl.nasa.gov/pub/eph/planets/ioms/ DE418_IOM_rev1.pdf
} 
The main contribution will come from the Gaia mission. This ESA astrometric mission, due for launch in early 2012, will pinpoint about 350000 asteroids - mainly main-belt asteroids down to $V=20 \mathrm{mag}$ with an unprecedented positional precision - at the sub-milliarcsecond level for single observation. Thus, numerous applications to asteroid science are expected (Mignard et al. 2007), including the determination of the masses of over 100 such bodies. With this unique level of astrometric accuracy, close approaches between two asteroids will show up as deviations of their unperturbed motion that would be unnoticed with standard sub-arcsec astrometry. Therefore the number of usable approaches will be very large with repeated occurrences during the mission lifetime of 5 years.

This method, which provided the first mass of an asteroid - (4) Vesta, Hertz 1966 - has remained the most productive. However, the accuracy of observations from the ground combined with the limited range of achievable solar elongations allows us to analyse only very significant gravitational signatures and explains in part the low number of known masses (54 with a precision better than 50\%). By pushing down the detection limit of gravitational perturbations and mitigating the constraints on solar elongation, Gaia will significantly increase the number of favourable encounters to be analysed. From calculations performed by considering realistic simulated data for Gaia - observation dates, geometry, time sequence, magnitude etc. - and the close approaches among 350000 asteroids from 2010.5 to 2016, it has been shown that 149 masses could be estimated with relative precision better than $50 \%$, with 36 under the $10 \%$ mark (Mouret et al. 2008). More important, several features of Gaia and data processing will limit the effects of systematic errors: the analysis will be carried out by using a refined dynamical modeling matching the astrometric accuracy. A global method is being developed to fit the masses by handling all perturbers and target asteroids simultaneously and including other general parameters of the dynamical model. From the simulations, we know that this will involve several thousands approaches above the detection threshold and that the global nature of the treatment will keep the systematic effects much lower than the random errors.

The Dawn mission (Russell et al. 2006, 2007) will have a non-negligible contribution in improving Mars' ephemeris. Launched on September 27, 2007, it is scheduled to be in orbit around (4) Vesta in 2011 and (1) Ceres in 2015 with the objective to characterise their internal structure and gravitational field: their masses will thus be derived with a precision that cannot be reached by other means. As a direct consequence, the strong perturbations of Mars by these two asteroids will be better modeled. This will help the Gaia solution as well since it will be possible to lessen the number of independent parameters by isolating the two strongest perturbers. They have a significant influence on the orbits of many smaller asteroids, among which a large number will be used as target asteroids to derive masses. In parallel they could also be used to assess the reliability of the formal errors in the Gaia solution, by including these two masses in the fit as true unknowns and comparing the result to the Dawn values, which will be much better than Gaia's.

Moreover, the masses of (1) Ceres and (4) Vesta obtained by Dawn will enable us to check the reliability of the method of estimating the masses from all data of spacecraft landing on or orbiting Mars, which gives the best formal precisions - which do not allow for systematic errors - for the three biggest asteroids and three other massive ones, (3) Juno, (7) Iris and (324) Bamberga. Indirectly, Dawn's data will allow a better mass estimates of the third most massive asteroid, (2) Pallas, by analyzing the perturbations on (1) Ceres: the latter is the asteroid that provided the most data to constrain its mass due to infrequent significant encounters between asteroids and (2) Pallas, which has an high inclination in comparison with most mainbelt asteroids. Furthermore, the well-known correlation between the a priori masses of these two asteroids, that Goffin (2001), and then Hilton (2002) tried to explain, is sufficiently large to cause further error on the computed mass. Then, it would be interesting to compare these mass estimates with those from spacecraft data orbiting Mars to determine the discrepancy. All this information could be valuable for the choice of the a priori mass of (2) Pallas in the Gaia process of mass determination.

\section{Input data of our analysis}

In 1984, only the mass of the three "bigs" was known from direct measurements. As a consequence, Williams had to estimate those of the remaining asteroids from guesses of their volume and density. The diameters were taken from the table of Bowell (1979) obtained from albedos, except for those of (2) Pallas and (3) Juno, both deduced from the occultations by Wasserman et al. (1979) and Millis et al. (1981). The density of (1) Ceres, that used to be estimated as $2.1 \mathrm{~g} \mathrm{~cm}^{-3}$, was taken as the reference. He then used more recent data to estimate asteroid physical properties and to constitute the list of 300 asteroids (1995).

Since then, our knowledge of asteroid masses has steadily improved with the constant increase of direct mass measurements or the observations of binary systems or flybys of asteroids and Mars. Furthermore, the indirect mass derivations - from a diameter estimate with an assumed density - have become slightly more precise and with more objects. Thus, the wider availability of electronic detectors has allowed us to increase the number of observations during the stellar occultations by an asteroid. Finally, we know the sizes from many new techniques and their combinations such as polarimetry, IR radiometry, adaptive optics, lightcurve inversion, radar, space probes etc. The usual sources of diameters are the IRAS Minor Planet Survey catalogue (Tedesco et al. 2004a) collecting 2228 asteroids - with the 2002 Supplemental IRAS Minor Planet Survey (SIMPS) - and the Midcourse Space Experiment Infrared Minor Planet Survey (MIMPS) (Tedesco et al. 2004b) including 168 asteroids. They were obtained by radiometric technique from infrared observations. Nevertheless, in spite of all these data, our knowledge of asteroid masses is far from being satisfactory.

Our analysis to find the most effective asteroids perturbing Mars was carried out with a subset of 2274 asteroids containing the 343 included in DE ephemerides, the asteroids with an IRAS or MIMPS diameter and those having a mass directly estimated with a precision better than $10 \%$. The assignment of a mass to each asteroid of the list is based on existing direct measurements (with a relative precision better than 10\%) or derived from an estimated diameter, assuming a density of $2.5 \mathrm{~g} \mathrm{~cm}^{-3}$ for an homogeneous spherical object. Instead of the simplistic approach of using one single bulk density for all objects, we could divide the sample of asteroids into several groups corresponding to the asteroid taxonomic classes. However, at present, the low number of available asteroid densities and their weak precision will not allow us to reliably establish a link, if any, between bulk density and taxonomic class. Current planetary ephemeris solutions provide an average density based on a division into three groups, corresponding to the taxonomic classes $\mathrm{C}, \mathrm{S}$ and M. This is however not fully satisfactory for two reasons. First, the new Bus asteroid taxonomy extended to the near-infrared by Demeo et al. (2008) has 24 classes, and spectroscopic observations give information only on the asteroid surface layers. 
Second, the macro-porosity is not taken into account, whereas it has a direct influence on the density, and discrepancies of porosities can be noticed within the same taxonomic classes (Britt et al. 2002). The diameters are taken first from the IRAS and MIMPS catalogues, and for the remaining asteroids, from occultations or the well-known empirical law depending on albedo and absolute magnitude. The initial osculating elements are from the database of Bowell ${ }^{5}$.

\section{Analytical treatment}

\subsection{Harmonic decomposition of the perturbations}

Our analytical investigation was performed in the spirit of Williams' paper (1984): from a software developed by Simon $(1986,1987)$, which permits us to express the theoretical perturbations $\Delta \sigma_{k}$ of an asteroid (to the first order in mass) on the six equinoctial elements of Mars $\sigma_{k=1, . .6}=(a, \lambda, k, h, q, p)$ during 1000 years.

$a$ is the orbital semi-major axis, $\lambda$ is the mean longitude, $k=e \cos \varpi, h=e \sin \varpi, q=\sin (i / 2) \cos \Omega, p=\sin (i / 2) \sin \Omega$, where $\varpi$ is the longitude of perihelion, $\Omega$ the longitude of the ascending node, $e$ the eccentricity, and $i$ the inclination. The method is based on harmonic decomposition with respect to the mean mean longitude of Mars $\bar{\lambda}$ and that of the asteroid $\bar{\lambda}^{\prime}$, which may be written as

$\bar{\lambda}=\lambda_{0}+\bar{n} t$,

$\bar{\lambda}^{\prime}=\lambda_{0}^{\prime}+\bar{n}^{\prime} t$,

where $t$ is the time, $\lambda_{0}$ and $\lambda_{0}^{\prime}$ are, respectively, the constants of integration of $\lambda$ and $\lambda^{\prime} . \bar{n}$ and $\bar{n}^{\prime}$ are the mean mean motions of Mars and of the asteroid and can be considered as being derived from observations. All these constants relative to the asteroid orbital elements are defined from Astorb's data and those relative to Mars' from DE405 (see Sect. 3).

$\Delta \sigma_{k}$ may be written as,

$\Delta \sigma_{k}\left(\bar{\lambda}, \bar{\lambda}^{\prime}\right)=\sigma_{k}^{\sec } t+\sum_{i, j} a_{i j}^{k} \cos \left(i \bar{\lambda}+j \bar{\lambda}^{\prime}\right)+b_{i j}^{k} \sin \left(i \bar{\lambda}+j \bar{\lambda}^{\prime}\right)$

where $\sigma_{k}^{\mathrm{sec}}$ is the secular term - which is not used in the analysis. We have applied this decomposition for each perturbation of our 2274 selected asteroids (Sect. 3) and focused on those that act upon the semi-major axis and longitude of Mars. We analyse the asteroids by selecting first the two amplitudes $c_{i j}^{k}=\left[\left(a_{i j}^{k}\right)^{2}+\left(b_{i j}^{k}\right)^{2}\right]^{1 / 2}(k=1,2)$ greater than two threshold values. They are defined as fractions of two coefficients found for (1) Ceres - a major perturber of Mars: $c_{\mathrm{a}}$ concerning the semimajor axis of Mars $(k=1)$ and $c_{\lambda}$ its longitude $(k=2)$, such that

$c_{\mathrm{a}}=\max _{i j}\left(c_{i j}^{1}\right), \quad c_{\lambda}=\max _{i j}\left(c_{i j}^{2}\right)$.

The values of these two coefficients are given in Table 2. The second filter consists in excluding the associated periods $P_{i j}^{k}$ superior to $P_{\text {lim }}=10$ years or 50 years $($ Table 1$)$, where

$P_{i j}^{k}=\frac{2 \pi}{i \times n_{\mathrm{M}}+j \times n^{\prime}}$,

with $i \in\{0,1, \ldots, 2 p-1\}$ and $j \in\left\{0,1, \ldots, 2 p^{\prime}-1\right\}$, and the case $(i=0, j=0)$ ruled out. $n_{\mathrm{M}}$ and $n^{\prime}$ are, respectively, the mean motions of Mars and the asteroid considered, and $p$ and $p^{\prime}$ two fixed integers. The two thresholds on the amplitudes, $c_{\mathrm{a}}$ and $c_{\lambda}$, are determined from the same filter on the period.

${ }^{5}$ URL: ftp://ftp. lowell .edu/pub/elgb/astorb.html

\subsection{Results}

In Table 1, we give, for each selected asteroid, the number of coefficients obtained in the expression of their perturbation on the semi-major axis $\Delta a_{\mathrm{M}}$ and the longitude $\Delta \lambda_{\mathrm{M}}$ of Mars for two filters on the period, $P<10$ years and $P<50$ years. The amplitudes are referred to two thresholds: one tenth and one hundredth of $c_{\mathrm{a}}$ and $c_{\lambda}$. The commensurability between the periods of Mars $P_{\mathrm{M}}$ and of asteroids $P_{\mathrm{a}}$ are given for information. The last column shows the expected formal precisions of less than $50 \%$ on the masses with Gaia (Mouret 2007), which have been recomputed by taking into account the updated mass estimates. In addition, the maximum amplitudes for $\Delta a_{\mathrm{M}}$ and $\Delta \lambda_{\mathrm{M}}$ with a period shorter than 50 years are given for each asteroid in Table 3. The complete list - referred to Table 1 - is provided in electronic form. The major role played by the three "bigs" on the Mars orbit is conspicuous in Table 1: they produce by far the greatest number of amplitudes for the semi-major axis and longitude of Mars, then followed by the asteroid (7) Iris. The amplitudes superior to the second limit $c_{\mathrm{a}} / 100$ and $c_{\lambda} / 100$ allow us to derive a second group of non-negligible asteroids: among them (3) Juno, (15) Eunomia, (654) Zelinda and (324) Bamberga. Except for the number of asteroids, the two lists $P<10$ and 50 years - are made up of almost the same asteroids among the most perturbing ones. More interestingly, we can notice that most of the asteroids that we selected by this first method will have a mass estimated by Gaia often with good precision and better than presently available. That gives a first hint of the future impact of Gaia in the modeling of the Mars ephemeris which will be treated in more detail in Sect. 7.

Because of the planetary perturbations, the orbital semimajor axis of asteroids changes together with their mean motion. Therefore, certain amplitudes associated with a particular combination of their longitudes and that of Mars can increase sharply, showing that they are likely to lie in an area where the resonances are close to each other and, thus, the transition from one to another is very easy. We performed several harmonic decompositions - 100 for each asteroid - similar to the previous ones by scanning the range of possible semi-major axes for each asteroid due to the planetary perturbations, which were obtained by numerical integrations over a period of 100 years. Table 4 lists the asteroids for which we obtain large variations in the amplitude, already strong in the reference case, with the number of amplitudes involved for the semi-major axis and the longitude of Mars. We found 27 asteroids among which five - (2) Pallas, (4) Vesta, (324) Bamberga, (10) Hygiea, (41) Daphne - are listed among the most important perturbers of Mars (Table 1). This table is in fact the list of the asteroids which would challenge the value of the fit of Mars if their orbits are themselves not well defined. Of course, the study does not take into account all other possibilities of resonances, in particular with Jupiter, which could have similar consequences and may shift or enhance possible resonances with Mars. Thus, the problem of fitting the Mars orbit will not be completely solved by the good knowledge of asteroid masses: the good fit of the orbits of certain asteroids probably will be at least as important as their mass estimates. The astrometric solution based on Gaia observations will help as well.

In addition, the harmonic decomposition of asteroid perturbations used previously is also able to give some information about the secular effects of each asteroid on the Martian orbit, which is interesting for its long-term analysis. More precisely, the constant of integration of the semi-major axis of Mars, $a_{0}$, is derived from the mean mean motion $\bar{n}$ in the following way. Let 
Table 1. Ranking of the asteroids according to the theoretical perturbations on the semi-major axis and longitude of Mars with periods smaller than 50 years.

\begin{tabular}{|c|c|c|c|c|c|c|c|c|c|c|c|c|}
\hline \multicolumn{2}{|c|}{ Asteroid } & \multicolumn{4}{|c|}{ Number of coeffs. $(P<50$ years $)$} & \multicolumn{4}{|c|}{ Number of coeffs. $(P<10$ years $)$} & \multirow{2}{*}{$\begin{array}{l}\text { Comm. } \\
P_{M}: P_{\mathrm{a}}\end{array}$} & \multirow{2}{*}{$\begin{array}{c}\text { Mass } \\
m \\
{\left[M_{\odot}\right]}\end{array}$} & \multirow{2}{*}{$\begin{array}{c}\sigma(m) / m \\
{[\%]}\end{array}$} \\
\hline $\mathrm{N}^{\mathrm{o}}$ & name & $\begin{array}{c}\Delta a_{\mathrm{M}} \\
c_{\mathrm{a}} / 10\end{array}$ & $\begin{array}{c}\Delta \lambda_{\mathrm{M}} \\
c_{\lambda} / 10\end{array}$ & $\begin{array}{c}\Delta a_{\mathrm{M}} \\
c_{\mathrm{a}} / 100\end{array}$ & $\begin{array}{c}\Delta \lambda_{\mathrm{M}} \\
c_{\lambda} / 100\end{array}$ & $\begin{array}{c}\Delta a_{\mathrm{M}} \\
c_{\mathrm{a}} / 10\end{array}$ & $\begin{array}{l}\Delta \lambda_{\mathrm{M}} \\
c_{\lambda} / 10\end{array}$ & $\begin{array}{c}\Delta a_{\mathrm{M}} \\
c_{\mathrm{a}} / 100\end{array}$ & $\begin{array}{c}\Delta \lambda_{\mathrm{M}} \\
c_{\lambda} / 100\end{array}$ & & & \\
\hline 1 & Ceres & 15 & 2 & 44 & 14 & 12 & 12 & 44 & 41 & - & $4.75 \times 10^{-10}$ & 0.07 \\
\hline 2 & Pallas & 9 & 2 & 52 & 13 & 6 & 7 & 56 & 48 & - & $1.03 \times 10^{-10}$ & 1.3 \\
\hline 4 & Vesta & 10 & 1 & 41 & 8 & 10 & 10 & 41 & 33 & - & $1.34 \times 10^{-10}$ & 0.09 \\
\hline 7 & Iris & 2 & 1 & 18 & 4 & - & - & 17 & 18 & - & $6.30 \times 10^{-12}$ & 3 \\
\hline 3 & Juno & - & - & 14 & 4 & - & 1 & 14 & 16 & - & $1.51 \times 10^{-11}$ & 2.4 \\
\hline 15 & Eunomia & - & - & 12 & 3 & - & 1 & 11 & 10 & - & $1.57 \times 10^{-11}$ & 1.8 \\
\hline 654 & Zelinda & - & - & 10 & 2 & - & - & 4 & 7 & - & $1.36 \times 10^{-12}$ & - \\
\hline 324 & Bamberga & - & - & 9 & 1 & - & - & 8 & 9 & $7: 3$ & $5.50 \times 10^{-12}$ & 12.1 \\
\hline 19 & Fortuna & - & - & 6 & 2 & - & - & 5 & 5 & - & $6.38 \times 10^{-12}$ & 3.1 \\
\hline 10 & Hygiea & - & - & 7 & - & - & - & 8 & 9 & - & $4.45 \times 10^{-11}$ & 0.8 \\
\hline 41 & Daphne $^{\star \star}$ & - & - & 5 & 2 & - & - & 2 & 7 & - & $3.47 \times 10^{-12}$ & 9.6 \\
\hline 532 & Herculina & - & - & 6 & 1 & - & - & 3 & 5 & - & $7.22 \times 10^{-12}$ & 8.2 \\
\hline 9 & Metis & - & - & 3 & 2 & - & - & 2 & 4 & - & $2.44 \times 10^{-12}$ & 10.8 \\
\hline 13 & Egeria & - & - & 4 & 1 & - & - & 2 & 2 & $11: 5$ & $5.89 \times 10^{-12}$ & 10.3 \\
\hline 344 & Desiderata & - & - & 3 & 2 & - & - & 1 & 3 & - & $1.52 \times 10^{-12}$ & - \\
\hline 511 & Davida & - & - & 5 & - & - & - & 6 & 8 & $3: 1$ & $2.20 \times 10^{-11}$ & 3.4 \\
\hline 6 & Hebe & - & - & 4 & - & - & - & 5 & 5 & $2: 1$ & $6.46 \times 10^{-12}$ & 6.9 \\
\hline 704 & Interamnia & - & - & 3 & 1 & - & - & 3 & 4 & - & $1.86 \times 10^{-11}$ & 4.3 \\
\hline 18 & Melpomene & - & - & 3 & - & - & - & 2 & 4 & - & $1.83 \times 10^{-12}$ & 21.2 \\
\hline 29 & Amphitrite & - & - & 2 & 1 & - & - & 2 & 3 & $13: 6$ & $5.92 \times 10^{-12}$ & 2.9 \\
\hline 8 & Flora & - & - & 2 & - & - & - & 2 & 4 & - & $1.65 \times 10^{-12}$ & 12.1 \\
\hline 14 & Irene & - & - & 2 & - & - & - & 1 & 3 & - & $2.31 \times 10^{-12}$ & 7.1 \\
\hline 27 & Euterpe & - & - & 2 & - & - & - & - & - & - & $5.82 \times 10^{-13}$ & 11.2 \\
\hline 51 & Nemausa & - & - & 1 & 1 & - & - & - & 1 & - & $2.13 \times 10^{-12}$ & 11.5 \\
\hline 105 & Artemis & - & - & 1 & 1 & - & - & - & - & - & $1.11 \times 10^{-12}$ & - \\
\hline 187 & Lamberta & - & - & 2 & - & - & - & - & 2 & $12: 5$ & $1.49 \times 10^{-12}$ & - \\
\hline 192 & Nausikaa & - & - & 1 & 1 & - & - & - & - & $2: 1$ & $7.25 \times 10^{-13}$ & 40.9 \\
\hline 313 & Chaldaea & - & - & 1 & 1 & - & - & - & - & - & $5.88 \times 10^{-13}$ & - \\
\hline 356 & Liguria & - & - & 1 & 1 & - & - & - & 1 & - & $1.49 \times 10^{-12}$ & 18.6 \\
\hline 405 & Thia & - & - & 2 & - & - & - & 1 & 2 & - & $1.28 \times 10^{-12}$ & 47.6 \\
\hline 419 & Aurelia & - & - & 1 & 1 & - & - & 1 & 2 & - & $1.41 \times 10^{-12}$ & 29.7 \\
\hline 747 & Winchester & - & - & 2 & - & - & - & 1 & 2 & - & $3.33 \times 10^{-12}$ & 30.4 \\
\hline 16 & Psyche & - & - & 1 & - & - & - & 3 & 4 & - & $1.10 \times 10^{-11}$ & 3.7 \\
\hline 409 & Aspasia & - & - & 1 & - & - & - & - & - & $11: 5$ & $2.78 \times 10^{-12}$ & 23 \\
\hline 451 & Patientia & - & - & 1 & - & - & - & 1 & 1 & - & $7.50 \times 10^{-12}$ & 6.8 \\
\hline 521 & Brixia & - & - & 1 & - & - & - & - & - & - & $1.02 \times 10^{-12}$ & - \\
\hline 31 & Euphrosyne & - & - & - & - & - & - & 2 & 4 & $3: 1$ & $1.10 \times 10^{-11}$ & 7.1 \\
\hline 20 & Massalia & - & - & - & - & - & - & 1 & 2 & $2: 1$ & $2.03 \times 10^{-12}$ & 8 \\
\hline 78 & Diana & - & - & - & - & - & - & - & 3 & $9: 4$ & $1.15 \times 10^{-12}$ & 24.0 \\
\hline 11 & Parthenope & - & - & - & - & - & - & 1 & 1 & - & $3.09 \times 10^{-12}$ & 5.5 \\
\hline 52 & Europa & - & - & - & - & - & - & 1 & 1 & - & $8.29 \times 10^{-12}$ & 4.6 \\
\hline 139 & Juewa & - & - & - & - & - & - & - & 2 & - & $2.53 \times 10^{-12}$ & 15.6 \\
\hline 194 & Prokne & - & - & - & - & - & - & 1 & 1 & $9: 4$ & $3.14 \times 10^{-12}$ & 18 \\
\hline 5 & Astraea & - & - & - & - & - & - & - & 1 & $11: 5$ & $1.11 \times 10^{-12}$ & 20.9 \\
\hline 12 & Victoria & - & - & - & - & - & - & - & 1 & - & $9.45 \times 10^{-13}$ & 13.2 \\
\hline 22 & Kalliope $e^{\star \star}$ & - & - & - & - & - & - & - & 1 & - & $4.07 \times 10^{-12}$ & 12.5 \\
\hline 23 & Thalia & - & - & - & - & - & - & - & 1 & - & $8.18 \times 10^{-13}$ & - \\
\hline 24 & Themis & - & - & - & - & - & - & - & 1 & - & $5.11 \times 10^{-12}$ & 10.5 \\
\hline 48 & Doris & - & - & - & - & - & - & - & 1 & - & $7.18 \times 10^{-12}$ & 6.3 \\
\hline 53 & Kalypso & - & - & - & - & - & - & - & 1 & $9: 4$ & $1.01 \times 10^{-12}$ & 20.5 \\
\hline 54 & Alexandra & - & - & - & - & - & - & - & 1 & - & $3.00 \times 10^{-12}$ & 7.8 \\
\hline 56 & Melete & - & - & - & - & - & - & - & 1 & - & $9.55 \times 10^{-13}$ & 38.1 \\
\hline 88 & Thisbe & - & - & - & - & - & - & 1 & - & - & $5.31 \times 10^{-12}$ & 3.4 \\
\hline 94 & Aurora & - & - & - & - & - & - & - & 1 & $3: 1$ & $5.66 \times 10^{-12}$ & 5.1 \\
\hline 111 & Ate & - & - & - & - & - & - & - & 1 & - & $1.60 \times 10^{-12}$ & 14.2 \\
\hline 144 & Vibilia & - & - & - & - & - & - & - & 1 & - & $1.88 \times 10^{-12}$ & 17 \\
\hline 145 & Adeona & - & - & - & - & - & - & _- & 1 & - & $2.27 \times 10^{-12}$ & 24.9 \\
\hline 156 & Xanthippe & - & - & - & - & - & - & - & 1 & $12: 5$ & $1.17 \times 10^{-12}$ & - \\
\hline 164 & Eva & - & - & - & - & - & - & - & 1 & - & $7.60 \times 10^{-13}$ & - \\
\hline 354 & Eleonora & - & - & - & - & - & - & - & 1 & $5: 2$ & $2.46 \times 10^{-12}$ & 16.6 \\
\hline 372 & Palma & - & - & - & - & - & - & - & 1 & $3: 1$ & $4.41 \times 10^{-12}$ & 32.3 \\
\hline 404 & Arsinoe & - & - & - & - & - & - & - & 1 & - & $6.14 \times 10^{-13}$ & - \\
\hline 423 & Diotima & - & - & - & - & - & - & - & 1 & - & $5.99 \times 10^{-12}$ & 4.1 \\
\hline 505 & Cava & - & - & - & - & - & - & - & 1 & $7: 3$ & $1.00 \times 10^{-12}$ & - \\
\hline
\end{tabular}

This gives essentially the number of perturbing terms (above two preselected thresholds) in the orbital elements of Mars due to the asteroids of Cols. 1 and 2. The same information is given for periods shorter than 10 years. The last column shows the expected formal precisions on the masses with Gaia when less than $50 \%$. The binary asteroids are marked by ${ }^{\star \star}$. 
Table 2. Values of $c_{\mathrm{a}}$ and $c_{\lambda}$ for the upper limits on the period of 10 and 50 years.

\begin{tabular}{cccc}
\hline \hline $\begin{array}{c}\text { Filters } \\
\text { in period }\end{array}$ & Argument & $\begin{array}{c}\text { Amplitude } \\
c_{\mathrm{a}} \\
{[\mathrm{AU}]}\end{array}$ & $\begin{array}{c}\text { Period } \\
P_{c_{\mathrm{a}}} \\
{[\text { years] }}\end{array}$ \\
\hline 10 years & $2 \bar{\lambda}_{\mathrm{M}}-2 \bar{\lambda}_{\mathrm{c}}$ & $3.31 \times 10^{-10}$ & 1.6 \\
50 years & $2 \bar{\lambda}_{\mathrm{M}}-5 \bar{\lambda}_{\mathrm{c}}$ & $4.05 \times 10^{-10}$ & 45.8 \\
\hline
\end{tabular}

\begin{tabular}{cccc}
\hline \hline $\begin{array}{c}\text { Filters } \\
\text { in period }\end{array}$ & Argument & $\begin{array}{c}\text { Amplitude } \\
c_{\lambda} \\
\text { [radian] }\end{array}$ & $\begin{array}{c}\text { Period } \\
P_{c_{\lambda}} \\
\text { [years] }\end{array}$ \\
\hline 10 years & $2 \bar{\lambda}_{\mathrm{M}}-4 \bar{\lambda}_{\mathrm{c}}$ & $6.15 \times 10^{-10}$ & 5.1 \\
50 years & $2 \bar{\lambda}_{\mathrm{M}}-5 \bar{\lambda}_{\mathrm{c}}$ & $9.28 \times 10^{-9}$ & 45.8 \\
\hline
\end{tabular}

The arguments are given as a combination of the mean motions of Mars $\bar{\lambda}_{\mathrm{M}}$ and of Ceres $\bar{\lambda}_{\mathrm{c}}$.

be $\epsilon_{1}$ the secular perturbations of the mean longitude of Mars due to the perturbing bodies and obtained by integrating the equations of the motion. Thus, we can write,

$\bar{n}=n_{0}+\epsilon_{1}$

where $n_{0}$ represents the integration constant of the mean motion $n$, and $a_{0}$ is derived from $n_{0}$ by Kepler's third law. So, taking into account the perturbations by the asteroids in the computation of $\epsilon_{1}$ results in modifying $n_{0}$ and $a_{0}$. We have thus drawn up a list of the asteroids in Table 5 having the greatest secular effects on the orbit of Mars from the value of $\epsilon_{1}$.

\section{Numerical treatment I}

\subsection{Using a selection software of close approaches}

A software written for the Gaia mission to search for close approaches between asteroids has been adapted to include Mars as one of the bodies. For each encounter, it computes the impulse effect on the orbit of Mars as a function of the asteroid mass. Over a period of 50 years extending from 2010 to 2060, we have summed all the deflections $\left(\theta_{1}\right.$ in the heliocentric reference frame) undergone by Mars due to a close (or not so close) encounter with one of the most massive asteroids. The orbits of asteroids are computed from the perturbations of all planets, and that of Mars is directly obtained from the JPL planetary ephemerides DE405 (Standish 1998). $\theta_{1}$ is obtained from the impulse approach (see Fig. 1) first computed in a Mars-centered frame, and then transferred in an heliocentric frame. The encounter velocities of our selected asteroids with Mars are relatively high and, consequently, the perturbation is distributed over a very short period of time compared to the orbital period, which justifies our use of the impulse approach. The angle $\theta_{1}$ may be written as

$\theta_{1}=\arctan \left(\frac{\left|\Delta \boldsymbol{V}_{M}\right|}{\left|\boldsymbol{V}_{M}\right|}\right)$,

where $\boldsymbol{V}_{M}$ is the heliocentric velocity of the perturbed object at the encounter time without considering the gravitational perturbation. $\Delta \boldsymbol{V}_{M}$ is the variation vector of its velocity due to the gravitational perturbation by a perturbing object with a mass $M$,

$\Delta \boldsymbol{V}_{M}=2 \frac{G M}{b V}\left(\boldsymbol{r}_{\mathrm{a}}-\boldsymbol{r}_{M}\right)$,

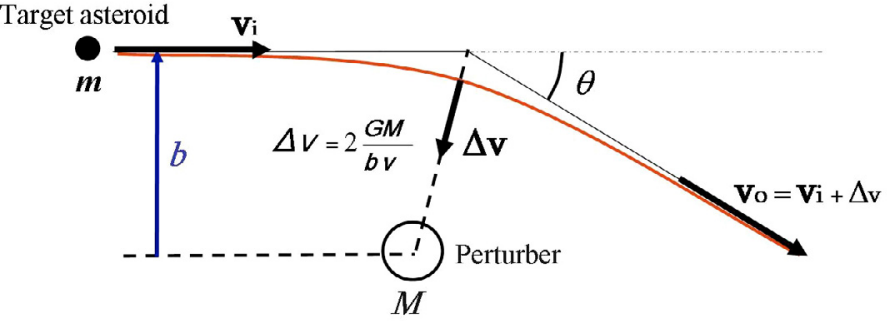

Fig. 1. Impulse approximation usually used to model the effect of the perturbation of a small target asteroid by a larger one during an encounter. The perturbed trajectory is represented by a hyperbola. $v_{i}$ and $v_{o}$ are, respectively, the incoming and outgoing velocity vectors. The effect of the perturbation is expressed by the vector $\Delta v$.

where $\boldsymbol{r}_{M}$ and $\boldsymbol{r}_{\mathrm{a}}$ are, respectively, the heliocentric position vectors of the perturbed and perturbing bodies. $b$ is the impact parameter theoretically defined as the initial length of the separation between the two asteroids perpendicular to the incoming velocity $V_{i}$ (see Fig. 1). When the impulse approach is applied to asteroid encounters, $b$ is reduced to the minimum distance between the two asteroid trajectories in the case where no scattering occurs, and $V$ is the relative velocity at this instant.

In our case, it is important to specify that the deflections are estimated to select the major perturbers of Mars and not to estimate their impact on its orbit. For simplification, the computation of $\theta_{1}$ described above was not strictly applied: firstly, we used the DE405 Mars ephemeris, yet, the latter was derived from the modeling of the perturbations of 300 asteroids, which are in our list of asteroids tested. For the sake of rigor, we should use for each perturber and each encounter a Mars solution built only with the perturbations of the remaining 299 asteroids during this encounter. The same holds for the orbit of the asteroid tested that we compute with the perturbation of Mars when estimating the impact parameter $b$ and the relative velocity $V$ at the closest approach. However, the characteristics of the encounters between Mars and main-belt asteroids are such that the discrepancies between the values of $b$ and $V$ obtained with and without our simplification are small compared to their values themselves, not resulting in significant change of the deflection angle value $\theta_{1}-$ this was numerically checked for several encounters. Our simplification has, thus, no consequence when selecting the perturbers from deflections of the Mars orbit.

\subsection{Results}

The selection of Mars perturbers was carried out by computing the sum of the multiple deflections of the trajectory of Mars, $\sum \theta_{1}$, caused by each asteroid. In Table 6 , the asteroids are listed according to three levels of perturbation strength. Among the first two groups $-\sum \theta_{1}>1$ mas and 0.1 mas $<\sum \theta_{1}<1$ mas bringing together the asteroids producing the largest deflections, we find again several of the asteroids listed in Table 1 (theoretical perturbations by harmonic decomposition). We also performed a similar selection by replacing the parameter $\theta_{1}$ with the parameter $P=M / b V$, which is a measure of the change of mean motion of the perturbed object, and is used in the selection process of close approaches (Galád 2001). Actually, the results were found to be very similar: among the first 50 asteroids selected, only one was different from our selection in Table 6. 
Table 3. List of the highest amplitudes with a period smaller than 50 years relating to the theoretical perturbations on the semi-major axis and longitude of Mars by each asteroid listed in Table 1.

\begin{tabular}{|c|c|c|c|c|c|c|c|}
\hline \multicolumn{2}{|c|}{ Asteroid } & \multicolumn{3}{|c|}{ Semi-major axis of Mars } & \multicolumn{3}{|c|}{ Longitude of Mars } \\
\hline $\mathrm{N}^{\mathrm{o}}$ & name & Argument & $\begin{array}{c}\text { Amplitude } \\
{[\mathrm{AU}]}\end{array}$ & $\begin{array}{l}\text { Period } \\
\text { [years] }\end{array}$ & Argument & $\begin{array}{l}\text { Amplitude } \\
\text { [radian] }\end{array}$ & $\begin{array}{l}\text { Period } \\
\text { [years] }\end{array}$ \\
\hline 1 & Ceres & $2 \bar{\lambda}_{\mathrm{M}}-5 \bar{\lambda}_{\mathrm{c}}$ & $4.05 \times 10^{-10}$ & 45.77 & $2 \bar{\lambda}_{\mathrm{M}}-5 \bar{\lambda}_{\mathrm{c}}$ & $9.28 \times 10^{-09}$ & 45.77 \\
\hline 2 & Pallas & $2 \bar{\lambda}_{\mathrm{M}}-5 \bar{\lambda}_{\mathrm{c}}$ & $4.97 \times 10^{-10}$ & 48.65 & $2 \bar{\lambda}_{\mathrm{M}}-5 \bar{\lambda}_{\mathrm{c}}$ & $1.23 \times 10^{-08}$ & 48.65 \\
\hline 4 & Vesta & $2 \bar{\lambda}_{\mathrm{M}}-4 \bar{\lambda}_{\mathrm{c}}$ & $2.59 \times 10^{-10}$ & 25.93 & $2 \bar{\lambda}_{\mathrm{M}}-4 \bar{\lambda}_{\mathrm{c}}$ & $3.24 \times 10^{-09}$ & 25.93 \\
\hline 7 & Iris & $2 \bar{\lambda}_{\mathrm{M}}-4 \bar{\lambda}_{\mathrm{c}}$ & $9.69 \times 10^{-11}$ & 46.45 & $2 \bar{\lambda}_{\mathrm{M}}-4 \bar{\lambda}_{\mathrm{c}}$ & $2.25 \times 10^{-09}$ & 46.45 \\
\hline 3 & Juno & $2 \bar{\lambda}_{\mathrm{M}}-4 \bar{\lambda}_{\mathrm{c}}$ & $2.46 \times 10^{-11}$ & 6.79 & $1 \bar{\lambda}_{\mathrm{M}}-2 \bar{\lambda}_{\mathrm{c}}$ & $1.37 \times 10^{-10}$ & 13.59 \\
\hline 15 & Eunomia & $2 \bar{\lambda}_{\mathrm{M}}-4 \bar{\lambda}_{\mathrm{c}}$ & $1.38 \times 10^{-11}$ & 7.55 & $3 \bar{\lambda}_{\mathrm{M}}-7 \bar{\lambda}_{\mathrm{c}}$ & $1.53 \times 10^{-10}$ & 29.28 \\
\hline 654 & Zelinda & $6 \bar{\lambda}_{\mathrm{M}}-11 \bar{\lambda}_{\mathrm{c}}$ & $1.30 \times 10^{-11}$ & 32.06 & $6 \bar{\lambda}_{\mathrm{M}}-11 \bar{\lambda}_{\mathrm{c}}$ & $2.26 \times 10^{-10}$ & 32.06 \\
\hline 324 & Bamberga & $2 \bar{\lambda}_{\mathrm{M}}-5 \bar{\lambda}_{\mathrm{c}}$ & $1.51 \times 10^{-11}$ & 13.80 & $2 \bar{\lambda}_{\mathrm{M}}-5 \bar{\lambda}_{\mathrm{c}}$ & $9.77 \times 10^{-11}$ & 13.80 \\
\hline 19 & Fortuna & $3 \bar{\lambda}_{\mathrm{M}}-6 \bar{\lambda}_{\mathrm{c}}$ & $1.75 \times 10^{-11}$ & 43.02 & $3 \bar{\lambda}_{\mathrm{M}}-6 \bar{\lambda}_{\mathrm{c}}$ & $4.09 \times 10^{-10}$ & 43.02 \\
\hline 10 & Hygiea & $2 \bar{\lambda}_{\mathrm{M}}-2 \bar{\lambda}_{\mathrm{c}}$ & $1.86 \times 10^{-11}$ & 1.42 & & & \\
\hline 41 & Daphne & $2 \bar{\lambda}_{\mathrm{M}}-5 \bar{\lambda}_{\mathrm{c}}$ & $2.52 \times 10^{-11}$ & 37.28 & $2 \bar{\lambda}_{\mathrm{M}}-5 \bar{\lambda}_{\mathrm{c}}$ & $4.69 \times 10^{-10}$ & 37.28 \\
\hline 532 & Herculina & $2 \bar{\lambda}_{\mathrm{M}}-5 \bar{\lambda}_{\mathrm{c}}$ & $2.72 \times 10^{-11}$ & 47.68 & $2 \bar{\lambda}_{\mathrm{M}}-5 \bar{\lambda}_{\mathrm{c}}$ & $6.56 \times 10^{-10}$ & 47.68 \\
\hline 9 & Metis & $2 \bar{\lambda}_{\mathrm{M}}-4 \bar{\lambda}_{\mathrm{c}}$ & $1.82 \times 10^{-11}$ & 45.61 & $2 \bar{\lambda}_{\mathrm{M}}-4 \bar{\lambda}_{\mathrm{c}}$ & $4.14 \times 10^{-10}$ & 45.61 \\
\hline 13 & Egeria & $1 \bar{\lambda}_{\mathrm{M}}-2 \bar{\lambda}_{\mathrm{c}}$ & $1.13 \times 10^{-11}$ & 20.59 & $1 \bar{\lambda}_{\mathrm{M}}-2 \bar{\lambda}_{\mathrm{c}}$ & $1.38 \times 10^{-10}$ & 20.59 \\
\hline 344 & Desiderata & $4 \bar{\lambda}_{\mathrm{M}}-9 \bar{\lambda}_{\mathrm{c}}$ & $9.08 \times 10^{-12}$ & 38.55 & $4 \bar{\lambda}_{\mathrm{M}}-9 \bar{\lambda}_{\mathrm{c}}$ & $1.77 \times 10^{-10}$ & 38.55 \\
\hline 511 & Davida & $2 \bar{\lambda}_{\mathrm{M}}-2 \bar{\lambda}_{\mathrm{c}}$ & $8.06 \times 10^{-12}$ & 1.41 & & & \\
\hline 6 & Hebe & $2 \bar{\lambda}_{\mathrm{M}}-3 \bar{\lambda}_{\mathrm{c}}$ & $8.85 \times 10^{-12}$ & 3.72 & & & \\
\hline 704 & Interamnia & $1 \bar{\lambda}_{\mathrm{M}}-3 \bar{\lambda}_{\mathrm{c}}$ & $1.43 \times 10^{-11}$ & 34.57 & $1 \bar{\lambda}_{\mathrm{M}}-3 \bar{\lambda}_{\mathrm{c}}$ & $2.37 \times 10^{-10}$ & 34.57 \\
\hline 18 & Melpomene & $2 \bar{\lambda}_{\mathrm{M}}-4 \bar{\lambda}_{\mathrm{c}}$ & $4.77 \times 10^{-12}$ & 11.58 & & & \\
\hline 29 & Amphitrite & $1 \bar{\lambda}_{\mathrm{M}}-2 \bar{\lambda}_{\mathrm{c}}$ & $1.28 \times 10^{-11}$ & 23.82 & $1 \bar{\lambda}_{\mathrm{M}}-2 \bar{\lambda}_{\mathrm{c}}$ & $1.80 \times 10^{-10}$ & 23.82 \\
\hline 8 & Flora & $3 \bar{\lambda}_{\mathrm{M}}-5 \bar{\lambda}_{\mathrm{c}}$ & $7.28 \times 10^{-12}$ & 15.54 & & & \\
\hline 14 & Irene & $1 \bar{\lambda}_{\mathrm{M}}-2 \bar{\lambda}_{\mathrm{c}}$ & $5.88 \times 10^{-12}$ & 19.55 & & & \\
\hline 27 & Euterpe & $1 \bar{\lambda}_{\mathrm{M}}-2 \bar{\lambda}_{\mathrm{c}}$ & $4.59 \times 10^{-12}$ & 40.81 & & & \\
\hline 51 & Nemausa & $2 \bar{\lambda}_{\mathrm{M}}-4 \bar{\lambda}_{\mathrm{c}}$ & $7.82 \times 10^{-12}$ & 27.50 & $2 \bar{\lambda}_{\mathrm{M}}-4 \bar{\lambda}_{\mathrm{c}}$ & $1.03 \times 10^{-10}$ & 27.50 \\
\hline 105 & Artemis & $2 \bar{\lambda}_{\mathrm{M}}-4 \bar{\lambda}_{\mathrm{c}}$ & $7.74 \times 10^{-12}$ & 33.72 & $2 \bar{\lambda}_{\mathrm{M}}-4 \bar{\lambda}_{\mathrm{c}}$ & $1.30 \times 10^{-10}$ & 33.72 \\
\hline 187 & Lamberta & $2 \bar{\lambda}_{\mathrm{M}}-5 \bar{\lambda}_{\mathrm{c}}$ & $5.85 \times 10^{-12}$ & 22.49 & & & \\
\hline 192 & Nausikaa & $4 \bar{\lambda}_{\mathrm{M}}-8 \bar{\lambda}_{\mathrm{c}}$ & $4.76 \times 10^{-12}$ & 48.14 & $4 \bar{\lambda}_{\mathrm{M}}-8 \bar{\lambda}_{\mathrm{c}}$ & $1.17 \times 10^{-10}$ & 48.14 \\
\hline 313 & Chaldaea & $2 \bar{\lambda}_{\mathrm{M}}-4 \bar{\lambda}_{\mathrm{c}}$ & $7.15 \times 10^{-12}$ & 33.49 & $2 \bar{\lambda}_{\mathrm{M}}-4 \bar{\lambda}_{\mathrm{c}}$ & $1.18 \times 10^{-10}$ & 33.49 \\
\hline 356 & Liguria & $2 \bar{\lambda}_{\mathrm{M}}-5 \bar{\lambda}_{\mathrm{c}}$ & $6.70 \times 10^{-12}$ & 34.78 & $2 \bar{\lambda}_{\mathrm{M}}-5 \bar{\lambda}_{\mathrm{c}}$ & $1.16 \times 10^{-10}$ & 34.78 \\
\hline 405 & Thia & $4 \bar{\lambda}_{\mathrm{M}}-9 \bar{\lambda}_{\mathrm{c}}$ & $4.50 \times 10^{-12}$ & 24.50 & & & \\
\hline 419 & Aurelia & $4 \bar{\lambda}_{\mathrm{M}}-9 \bar{\lambda}_{\mathrm{c}}$ & $4.92 \times 10^{-12}$ & 39.28 & $4 \bar{\lambda}_{\mathrm{M}}-9 \bar{\lambda}_{\mathrm{c}}$ & $9.70 \times 10^{-11}$ & 39.28 \\
\hline 747 & Winchester & $2 \bar{\lambda}_{\mathrm{M}}-5 \bar{\lambda}_{\mathrm{c}}$ & $5.09 \times 10^{-12}$ & 9.89 & & & \\
\hline 16 & Psyche & $2 \bar{\lambda}_{\mathrm{M}}-2 \bar{\lambda}_{\mathrm{c}}$ & $6.20 \times 10^{-12}$ & 1.51 & & & \\
\hline 409 & Aspasia & $1 \bar{\lambda}_{\mathrm{M}}-2 \bar{\lambda}_{\mathrm{c}}$ & $4.88 \times 10^{-12}$ & 20.96 & & & \\
\hline 451 & Patientia & $1 \bar{\lambda}_{\mathrm{M}}-3 \bar{\lambda}_{\mathrm{c}}$ & $4.38 \times 10^{-12}$ & 36.43 & & & \\
\hline 521 & Brixia & $2 \bar{\lambda}_{\mathrm{M}}-5 \bar{\lambda}_{\mathrm{c}}$ & $4.16 \times 10^{-12}$ & 25.11 & & & \\
\hline
\end{tabular}

\section{Numerical treatment II}

In this section, we investigate the drift of the orbital semi-major axis $a$, eccentricity $e$, and inclination $i$ of Mars due to the asteroid perturbations over a short period of time. Since most of the orbital change follows from the planetary perturbation, we look at the difference between the perturbations caused by the planets and that caused by the planets and one of the test asteroids. The perturbations of the other asteroids usually considered in modeling the Mars ephemeris are not allowed for. Indeed, our objective is only to select the major perturbers of Mars, not to quantify the impact of each asteroid on Mars's motion. The numerical integration is performed over 50 years and the drift of each of the three orbital parameters is computed by sampling this interval about every month, including one asteroid at a time. The difference of rate is the basic signature of the influence of a particular asteroid. For the semi-major axis of Mars, the drift can be seen as the expression of the largest periodic perturbing terms over 50 years that we analytically found in Sect. 4 .

The asteroids have been ordered in decreasing order of their effect on each orbital parameter of Mars, and thus three lists have been drawn up by retaining the first 50 asteroids. As, the results do not change the final list of Mars' perturbers (see Sect. 7), they are only listed in Table 7 summarizing the results.

\section{Synthesis and prospects}

Our results are summarised in Table 7, where the asteroids are ranked with respect to the number of times they have been selected from all methods. In this table, the IAU designation and the name of the asteroid are given, and the methods by which it was selected are marked by a cross. The column H.D corresponds to the theoretical determination by harmonic decomposition of perturbations on the semi-major axis and the longitude of Mars for the two filters 10 and 100 (period $P<50$ years). The column $\sum \theta_{1}$ is from Table 6 and its three hierarchic groups, and Linear Reg. from Sect. 6. We also indicate if the asteroid was selected in the first selection of Williams (1984) and if it is considered as a major perturber of Mars in the DE ephemeris. The asteroid masses are then given with the standard deviations expected with Gaia - less than $50 \%$. Also, we list, for information, the commensurabilities between the periods of Mars $P_{\mathrm{M}}$ and of 
Table 4. Asteroids for which some coefficients with a period shorter than 100 years change by at least $100 \%$ with the variation of the semimajor axis.

\begin{tabular}{|c|c|c|c|c|}
\hline \multicolumn{2}{|c|}{ Asteroid } & \multicolumn{2}{|c|}{ Number of coeffs. } & \multirow{2}{*}{$\begin{array}{c}\sigma(m) / m \\
{[\%]}\end{array}$} \\
\hline $\mathrm{N}^{0}$ & name & $\Delta a$ & $\Delta \lambda_{\mathrm{M}}$ & \\
\hline 2 & Pallas & 2 & 13 & 1.3 \\
\hline 4 & Vesta & 0 & 2 & 0.09 \\
\hline 10 & Hygiea & 0 & 5 & 0.8 \\
\hline 13 & Egeria & 4 & 2 & 10.3 \\
\hline 14 & Irene & 0 & 9 & 7.1 \\
\hline 24 & Themis & 0 & 10 & 10.5 \\
\hline 28 & Bellona & 0 & 1 & - \\
\hline 41 & Daphne & 10 & 11 & 9.6 \\
\hline 51 & Nemausa & 0 & 1 & 11.5 \\
\hline 74 & Galatea & 0 & 3 & 19.4 \\
\hline 88 & Thisbe & 0 & 1 & 3.4 \\
\hline 98 & Ianthe & 0 & 6 & - \\
\hline 139 & Juewa & 0 & 11 & 15.6 \\
\hline 181 & Eucharis & 0 & 5 & - \\
\hline 275 & Sapientia & 0 & 1 & 43. \\
\hline 324 & Bamberga & 0 & 5 & 12.1 \\
\hline 344 & Desiderata & 0 & 3 & - \\
\hline 356 & Liguria & 8 & 0 & 18.6 \\
\hline 372 & Palma & 0 & 10 & 32.3 \\
\hline 393 & Lampetia & 1 & 12 & - \\
\hline 405 & Thia & 0 & 5 & 47.6 \\
\hline 415 & Palatia & 0 & 14 & - \\
\hline 511 & Davida & 1 & 0 & 3.4 \\
\hline 521 & Brixia & 0 & 4 & - \\
\hline 532 & Herculina & 0 & 3 & 8.2 \\
\hline 704 & Interamnia & 0 & 1 & 4.3 \\
\hline 1093 & Freda & 0 & 1 & - \\
\hline
\end{tabular}

The expected standard deviations with Gaia marked by "-" mean that they are greater than $50 \%$.

asteroids $P_{\mathrm{a}}$ as well as whether the first 50 asteroids in terms of secular effects on the Mars orbit belong to this list (see Table 5).

Table 7 cannot be used as a strict ranking list because it counts only the appearance in the tables, which partially reflects the importance of an asteroid upon the Mars orbit. The rank is not taken into account, because it would be difficult to weight it knowing that the methods used are very different. Nevertheless, we find the three "bigs" at the top of the list which are usually considered as the most perturbing.

Even if our objectives differ somewhat from earlier related works, the comparison of the results is interesting. As for the first study in 1984, 32 objects had been selected by Williams in studying asteroid perturbations of the mean longitude of Mars and also their resonances, which can be read in his list of 300 perturbers resulting from a more advanced work. By considering the 67 "major" of the 343 asteroids provided later by Standish, 50 are in our list in spite of the differences in selection - the initial conditions of asteroids, estimation of masses, the period of time studied, the methods themselves, the objectives etc. As for the other 12 asteroids - from our results in Table 7 -, (154) Bertha and (313) Chaldea seem to be the most important.

Keeping in mind that the number of asteroids we found is entirely dependent on our arbitrary selection threshold, about sixty asteroids picked out as major or being potentially so are enough to already see the potential of Gaia to improve, albeit indirectly, the ephemeris of Mars. Among the 62 asteroids listed, 53 mass determinations are expected with a precision better than $50 \%$, and even often below the $10 \%$ mark (27 out of 53). These
Table 5. Asteroids ranked according to their secular effects on the Mars orbit.

\begin{tabular}{|c|c|c|c|c|c|}
\hline \multicolumn{2}{|c|}{ Asteroid } & \multirow[t]{2}{*}{$\epsilon_{1}$} & \multicolumn{2}{|c|}{ Asteroid } & \multirow[t]{2}{*}{$\epsilon_{1}$} \\
\hline $\mathrm{N}^{\mathrm{o}}$ & name & & $\mathrm{N}^{\mathrm{o}}$ & name & \\
\hline 1 & Ceres & 1.000 & 65 & Cybele ${ }^{\text {*t }}$ & 0.009 \\
\hline 4 & Vesta & 0.564 & 31 & Euphrosyne & 0.008 \\
\hline 10 & Hygiea & 0.061 & 51 & Nemausa & 0.008 \\
\hline 2 & Pallas & 0.057 & 423 & Diotima & 0.008 \\
\hline 15 & Eunomia & 0.037 & 18 & Melpomene & 0.008 \\
\hline 3 & Juno & 0.034 & 24 & Themis & 0.008 \\
\hline 7 & Iris & 0.031 & 41 & Daphne & 0.008 \\
\hline 511 & Davida & 0.026 & 14 & Irene & 0.007 \\
\hline 19 & Fortuna & 0.025 & 94 & Aurora & 0.007 \\
\hline 704 & Interamnia & 0.021 & 375 & Ursula ${ }^{\ddagger}$ & 0.007 \\
\hline 16 & Psyche & 0.020 & 409 & Aspasia & 0.007 \\
\hline 6 & Hebe & 0.019 & 45 & Eugenia $^{\ddagger}$ & 0.007 \\
\hline 29 & Amphitrite & 0.018 & 22 & Kalliope & 0.006 \\
\hline 324 & Bamberga & 0.015 & 54 & Alexandra & 0.006 \\
\hline 532 & Herculina & 0.013 & 59 & Elpis ${ }^{\ddagger}$ & 0.006 \\
\hline 13 & Egeria & 0.013 & 87 & Sylvia & 0.006 \\
\hline 52 & Europa & 0.012 & 139 & Juewa & 0.006 \\
\hline 88 & Thisbe & 0.011 & 194 & Prokne & 0.006 \\
\hline 9 & Metis & 0.011 & 145 & Adeona & 0.006 \\
\hline 11 & Parthenope & 0.011 & 144 & Vibilia & 0.005 \\
\hline 8 & Flora & 0.010 & 85 & $\mathrm{Io}^{\$}$ & 0.005 \\
\hline 128 & Nemesis & 0.010 & 444 & Gyptis & 0.005 \\
\hline 20 & Massalia & 0.010 & 89 & Julia $^{\ddagger}$ & 0.005 \\
\hline 48 & Doris & 0.010 & 21 & Lutetia $^{\text {粆 }}$ & 0.005 \\
\hline 451 & Patientia & 0.009 & 111 & Ate & 0.005 \\
\hline
\end{tabular}

The values of $\epsilon_{1}$ are normalized to that found for (1) Ceres. The asteroids that are not in Table 1 are marked by

Table 6. Ranking of the asteroids according to the cumulative deflections $\theta_{1}$ (in mas) of the Mars orbit over a period of 50 years from 2010.

\begin{tabular}{|c|c|c|c|c|c|}
\hline \multicolumn{2}{|c|}{ Asteroid } & $\sum_{[\mathrm{mas}]} \theta_{1}$ & \multicolumn{2}{|c|}{ Asteroid } & $\sum_{[\mathrm{mas}]}^{\sum \theta_{1}}$ \\
\hline 1 & Ceres & 15.856 & 31 & Euphrosyne & 0.128 \\
\hline 4 & Vesta & 7.275 & 8 & Flora & 0.125 \\
\hline 2 & Pallas & 1.326 & 11 & Parthenope & 0.122 \\
\hline 10 & Hygiea & 1.301 & 375 & Ursula & 0.122 \\
\hline & & & 94 & Aurora & 0.122 \\
\hline 15 & Eunomia & 0.483 & 87 & Sylvia & 0.121 \\
\hline 3 & Juno & 0.357 & 145 & Adeona & 0.116 \\
\hline 7 & Iris & 0.355 & 356 & Liguria & 0.105 \\
\hline 511 & Davida & 0.354 & 22 & Kalliope & 0.103 \\
\hline 704 & Interamnia & 0.311 & 107 & Camilla & 0.103 \\
\hline 16 & Psyche & 0.274 & & & \\
\hline 13 & Egeria & 0.232 & 51 & Nemausa & 0.094 \\
\hline 29 & Amphitrite & 0.232 & 59 & Elpis & 0.093 \\
\hline 6 & Hebe & 0.214 & 18 & Melpomene & 0.093 \\
\hline 532 & Herculina & 0.207 & 76 & Freia & 0.091 \\
\hline 14 & Irene & 0.205 & 45 & Eugenia & 0.091 \\
\hline 52 & Europa & 0.202 & 154 & Bertha & 0.085 \\
\hline 19 & Fortuna & 0.197 & 194 & Prokne & 0.084 \\
\hline 24 & Themis & 0.176 & 54 & Alexandra & 0.083 \\
\hline 65 & Cybele & 0.167 & 120 & Lachesis & 0.082 \\
\hline 324 & Bamberga & 0.164 & 27 & Euterpe & 0.082 \\
\hline 451 & Patientia & 0.155 & 409 & Aspasia & 0.080 \\
\hline 48 & Doris & 0.154 & 41 & Daphne & 0.080 \\
\hline 88 & Thisbe & 0.146 & 144 & Vibilia & 0.077 \\
\hline 423 & Diotima & 0.134 & 747 & Winchester & 0.076 \\
\hline 128 & Nemesis & 0.128 & 96 & Aegle & 0.074 \\
\hline
\end{tabular}


Table 7. List of asteroids identified as potential major perturbers of Mars.

\begin{tabular}{|c|c|c|c|c|c|c|c|c|c|c|c|c|c|c|c|c|}
\hline \multicolumn{2}{|c|}{ Asteroid } & \multicolumn{2}{|c|}{ H.D } & \multicolumn{3}{|c|}{$\sum \theta_{1}$} & \multicolumn{3}{|c|}{ Linear Reg. } & \multirow[t]{2}{*}{$\sum \mathrm{X}$} & \multirow{2}{*}{$\begin{array}{c}\text { Williams } \\
(1984)\end{array}$} & \multirow{2}{*}{$\begin{array}{l}\text { "Major" } \\
\text { JPL }\end{array}$} & \multirow{2}{*}{$\begin{array}{c}m \\
{\left[M_{\odot}\right]}\end{array}$} & \multirow{2}{*}{$\begin{array}{c}\sigma(m) / m \\
{[\%]}\end{array}$} & Comm. & Secular \\
\hline $\mathrm{N}^{\mathrm{o}}$ & name & 10 & 100 & 1 & 2 & 3 & $a$ & $e$ & $i$ & & & & & & $P_{\mathrm{M}}: P_{\mathrm{a}}$ & effects \\
\hline 1 & Ceres & $\mathrm{x}$ & $\mathrm{x}$ & $\mathrm{x}$ & - & - & $\mathrm{x}$ & $\mathrm{x}$ & $\mathrm{x}$ & 6 & $\mathrm{x}$ & $\mathrm{x}$ & $4.75 \times 10^{-10}$ & 0.07 & - & $\mathrm{x}$ \\
\hline 2 & Pallas & $\mathrm{X}$ & $\mathrm{X}$ & $\mathrm{x}$ & - & - & $\mathrm{X}$ & $\mathrm{X}$ & $\mathrm{X}$ & 6 & $\mathrm{X}$ & $\mathrm{x}$ & $1.03 \times 10^{-10}$ & 1.3 & - & $\mathrm{X}$ \\
\hline 4 & Vesta & $\mathrm{x}$ & $\mathrm{X}$ & $\mathrm{x}$ & - & - & $\mathrm{x}$ & $\mathrm{X}$ & $\mathrm{X}$ & 6 & $\mathrm{x}$ & $\mathrm{x}$ & $1.34 \times 10^{-10}$ & 0.09 & - & $\mathrm{x}$ \\
\hline 7 & Iris & $\mathrm{X}$ & $\mathrm{X}$ & - & $\mathrm{x}$ & - & $\mathrm{X}$ & $\mathrm{X}$ & $\mathrm{X}$ & 6 & $\mathrm{X}$ & $\mathrm{X}$ & $6.30 \times 10^{-12}$ & 3.0 & - & $\mathrm{X}$ \\
\hline 3 & Juno & - & $\mathrm{X}$ & - & $\mathrm{X}$ & - & $\mathrm{x}$ & $\mathrm{x}$ & $\mathrm{x}$ & 5 & $\mathrm{X}$ & $\mathrm{x}$ & $1.51 \times 10^{-11}$ & 2.4 & - & $\mathrm{X}$ \\
\hline 6 & Hebe & - & $\mathrm{X}$ & - & $\mathrm{X}$ & - & $\mathrm{X}$ & $\mathrm{X}$ & $\mathrm{x}$ & 5 & $\mathrm{X}$ & $\mathrm{x}$ & $6.46 \times 10^{-12}$ & 6.9 & $2: 1$ & $\mathrm{x}$ \\
\hline 8 & Flora & - & $\mathrm{X}$ & - & $\mathrm{X}$ & - & $\mathrm{X}$ & $\mathrm{x}$ & $\mathrm{x}$ & 5 & $\mathrm{x}$ & $\mathrm{x}$ & $1.65 \times 10^{-12}$ & 12.1 & - & $\mathrm{X}$ \\
\hline 10 & Hygiea & - & $\mathrm{X}$ & $\mathrm{x}$ & - & - & $\mathrm{x}$ & $\mathrm{X}$ & $\mathrm{X}$ & 5 & $\mathrm{x}$ & $\mathrm{x}$ & $4.45 \times 10^{-11}$ & 0.8 & - & $\mathrm{x}$ \\
\hline 14 & Irene & - & $\mathrm{X}$ & - & $\mathrm{X}$ & - & $\mathrm{x}$ & $\mathrm{x}$ & $\mathrm{x}$ & 5 & $\mathrm{x}$ & $\mathrm{x}$ & $2.31 \times 10^{-12}$ & 7.1 & - & $\mathrm{x}$ \\
\hline 51 & Nemausa & - & $\mathrm{X}$ & - & - & $\mathrm{x}$ & $\mathrm{X}$ & $\mathrm{X}$ & $\mathrm{X}$ & 5 & $\mathrm{X}$ & $\mathrm{x}$ & $2.13 \times 10^{-12}$ & 11.5 & - & $\mathrm{x}$ \\
\hline 324 & Bamberga & - & $\mathrm{X}$ & - & $\mathrm{x}$ & - & $\mathrm{x}$ & $\mathrm{x}$ & $\mathrm{x}$ & 5 & $\mathrm{x}$ & $\mathrm{x}$ & $5.50 \times 10^{-12}$ & 12.1 & $7: 3$ & $\mathrm{x}$ \\
\hline 511 & Davida & - & $\mathrm{X}$ & - & $\mathrm{X}$ & - & $\mathrm{X}$ & $\mathrm{X}$ & $\mathrm{X}$ & 5 & $\mathrm{x}$ & $\mathrm{x}$ & $2.20 \times 10^{-11}$ & 3.4 & $3: 1$ & $\mathrm{X}$ \\
\hline 532 & Herculina & - & $\mathrm{X}$ & - & $\mathrm{X}$ & - & $\mathrm{x}$ & $\mathrm{x}$ & $\mathrm{x}$ & 5 & $\mathrm{X}$ & $\mathrm{x}$ & $7.22 \times 10^{-12}$ & 8.2 & - & $\mathrm{X}$ \\
\hline 11 & Parthenope & - & - & - & $\mathrm{X}$ & _- & $\mathrm{x}$ & $\mathrm{x}$ & $\mathrm{x}$ & 4 & - & $\mathrm{x}$ & $3.09 \times 10^{-12}$ & 5.5 & - & $\mathrm{x}$ \\
\hline 15 & Eunomia & - & $\mathrm{X}$ & - & $\mathrm{X}$ & - & - & $\mathrm{X}$ & $\mathrm{X}$ & 4 & $\mathrm{X}$ & $\mathrm{x}$ & $1.57 \times 10^{-11}$ & 1.8 & - & $\mathrm{X}$ \\
\hline 18 & Melpomene & - & $\mathrm{X}$ & - & - & $\mathrm{x}$ & $\mathrm{X}$ & - & $\mathrm{X}$ & 4 & $\mathrm{X}$ & $\mathrm{x}$ & $1.83 \times 10^{-12}$ & 21.2 & - & $\mathrm{x}$ \\
\hline 29 & Amphitrite & - & $\mathrm{X}$ & - & $\mathrm{X}$ & - & - & $\mathrm{x}$ & $\mathrm{x}$ & 4 & $\mathrm{x}$ & $\mathrm{X}$ & $5.92 \times 10^{-12}$ & 2.9 & 13:6 & $\mathrm{X}$ \\
\hline 41 & Daphne ${ }^{\star \star}$ & - & $\mathrm{X}$ & - & - & $\mathrm{x}$ & - & $\mathrm{X}$ & $\mathrm{X}$ & 4 & $\mathrm{X}$ & $\mathrm{x}$ & $3.47 \times 10^{-12}$ & 9.6 & - & $\mathrm{X}$ \\
\hline 52 & Europa & - & - & - & $\mathrm{X}$ & - & $\mathrm{x}$ & $\mathrm{x}$ & $\mathrm{x}$ & 4 & $\mathrm{X}$ & $\mathrm{x}$ & $8.29 \times 10^{-12}$ & 4.6 & - & $\mathrm{x}$ \\
\hline 654 & Zelinda & - & $\mathrm{X}$ & - & - & - & $\mathrm{x}$ & $\mathrm{x}$ & $\mathrm{x}$ & 4 & - & $\mathrm{x}$ & $1.36 \times 10^{-12}$ & - & - & - \\
\hline 704 & Interamnia & - & $\mathrm{X}$ & - & $\mathrm{X}$ & - & - & $\mathrm{x}$ & $\mathrm{x}$ & 4 & $\mathrm{x}$ & $\mathrm{x}$ & $1.86 \times 10^{-11}$ & 4.3 & - & $\mathrm{x}$ \\
\hline 747 & Winchester & - & $\mathrm{X}$ & - & - & $\mathrm{x}$ & $\mathrm{x}$ & - & $\mathrm{x}$ & 4 & $\mathrm{x}$ & $\mathrm{x}$ & $3.33 \times 10^{-12}$ & 30.4 & - & - \\
\hline 9 & Metis & - & $\mathrm{X}$ & - & - & - & $\mathrm{x}$ & $\mathrm{x}$ & - & 3 & $\mathrm{x}$ & $\mathrm{x}$ & $2.44 \times 10^{-12}$ & 10.8 & - & $\mathrm{X}$ \\
\hline 16 & Psyche & - & $\mathrm{X}$ & - & $\mathrm{X}$ & - & - & - & $\mathrm{x}$ & 3 & $\mathrm{x}$ & $\mathrm{x}$ & $1.10 \times 10^{-11}$ & 3.7 & - & $\mathrm{x}$ \\
\hline 19 & Fortuna & - & $\mathrm{X}$ & - & $\mathrm{X}$ & - & - & $\mathrm{X}$ & - & 3 & $\mathrm{X}$ & $\mathrm{x}$ & $6.38 \times 10^{-12}$ & 3.1 & - & $\mathrm{x}$ \\
\hline 24 & Themis & - & - & - & $\mathrm{X}$ & - & $\mathrm{X}$ & $\mathrm{X}$ & - & 3 & $\mathrm{X}$ & $\mathrm{x}$ & $5.11 \times 10^{-12}$ & 10.5 & - & $\mathrm{x}$ \\
\hline 31 & Euphrosyne & - & - & - & $\mathrm{X}$ & - & - & $\mathrm{x}$ & $\mathrm{x}$ & 3 & $\mathrm{x}$ & $\mathrm{x}$ & $1.10 \times 10^{-11}$ & 7.1 & $3: 1$ & $\mathrm{X}$ \\
\hline 94 & Aurora & - & - & - & $\mathrm{X}$ & - & $\mathrm{X}$ & $\mathrm{X}$ & - & 3 & - & $\mathrm{x}$ & $5.66 \times 10^{-12}$ & 5.1 & $3: 1$ & $\mathrm{X}$ \\
\hline 105 & Artemis & - & $\mathrm{X}$ & - & - & - & $\mathrm{x}$ & $\mathrm{X}$ & - & 3 & - & $\mathrm{x}$ & $1.11 \times 10^{-12}$ & - & - & - \\
\hline 130 & Elektra $^{\star \star}$ & - & - & - & - & - & $\mathrm{X}$ & $\mathrm{X}$ & $\mathrm{X}$ & 3 & - & - & $3.32 \times 10^{-12}$ & - & - & - \\
\hline 145 & Adeona & - & - & - & $\mathrm{X}$ & - & $\mathrm{x}$ & - & $\mathrm{x}$ & 3 & - & $\mathrm{x}$ & $2.27 \times 10^{-12}$ & 24.9 & - & $\mathrm{x}$ \\
\hline 154 & Bertha & - & - & - & - & $\mathrm{x}$ & $\mathrm{X}$ & $\mathrm{X}$ & - & 3 & - & - & $4.16 \times 10^{-12}$ & - & - & - \\
\hline 192 & Nausikaa & - & $\mathrm{X}$ & - & - & - & $\mathrm{X}$ & $\mathrm{x}$ & - & 3 & - & $\mathrm{x}$ & $7.25 \times 10^{-13}$ & 40.9 & $2: 1$ & - \\
\hline 194 & Prokne & - & - & - & - & $\mathrm{x}$ & $\mathrm{x}$ & - & $\mathrm{X}$ & 3 & - & $\mathrm{x}$ & $3.14 \times 10^{-12}$ & 18.0 & $9: 4$ & $\mathrm{X}$ \\
\hline 313 & Chaldaea & - & $\mathrm{X}$ & - & - & - & $\mathrm{x}$ & $\mathrm{x}$ & - & 3 & - & - & $5.88 \times 10^{-13}$ & - & - & - \\
\hline 375 & Ursula & - & - & - & $\mathrm{X}$ & - & - & $\mathrm{X}$ & $\mathrm{X}$ & 3 & - & - & $6.63 \times 10^{-12}$ & 11.4 & - & $\mathrm{X}$ \\
\hline 451 & Patientia & - & $\mathrm{X}$ & - & $\mathrm{X}$ & - & - & - & $\mathrm{x}$ & 3 & - & $\mathrm{x}$ & $7.50 \times 10^{-12}$ & 6.8 & - & $\mathrm{X}$ \\
\hline 5 & Astraea & - & - & - & - & - & $\mathrm{X}$ & $\mathrm{x}$ & - & 2 & - & $\mathrm{x}$ & $1.11 \times 10^{-12}$ & 20.9 & $11: 5$ & - \\
\hline 13 & Egeria & - & $\mathrm{X}$ & - & $\mathrm{X}$ & - & - & - & - & 2 & $\mathrm{X}$ & $\mathrm{X}$ & $5.89 \times 10^{-12}$ & 10.3 & $11: 5$ & $\mathrm{X}$ \\
\hline 20 & Massalia & - & - & - & - & - & $\mathrm{X}$ & $\mathrm{X}$ & - & 2 & $\mathrm{X}$ & $\mathrm{x}$ & $2.03 \times 10^{-12}$ & 8.0 & $2: 1$ & $\mathrm{x}$ \\
\hline 27 & Euterpe & - & $\mathrm{X}$ & - & - & $\mathrm{x}$ & - & - & - & 2 & - & $\mathrm{x}$ & $5.82 \times 10^{-13}$ & 11.2 & - & - \\
\hline 45 & Eugenia ${ }^{\star \star}$ & - & - & - & - & $\mathrm{x}$ & - & - & $\mathrm{X}$ & 2 & $\mathrm{X}$ & $\mathrm{x}$ & $2.82 \times 10^{-12}$ & 3.1 & - & $\mathrm{X}$ \\
\hline 48 & Doris & - & - & - & $\mathrm{X}$ & - & - & - & $\mathrm{X}$ & 2 & - & - & $7.18 \times 10^{-12}$ & 6.3 & - & $\mathrm{X}$ \\
\hline 54 & Alexandra & - & - & - & - & $\mathrm{x}$ & - & - & $\mathrm{X}$ & 2 & - & - & $3.00 \times 10^{-12}$ & 7.8 & - & $\mathrm{X}$ \\
\hline 59 & Elpis & - & - & - & - & $\mathrm{x}$ & - & - & $\mathrm{X}$ & 2 & - & - & $2.95 \times 10^{-12}$ & 9.1 & - & $\mathrm{X}$ \\
\hline 63 & Ausonia & - & - & - & - & - & $\mathrm{X}$ & $\mathrm{X}$ & - & 2 & - & $\mathrm{x}$ & $7.21 \times 10^{-13}$ & - & $2: 1$ & - \\
\hline 78 & Diana & - & - & - & - & - & $\mathrm{x}$ & - & $\mathrm{x}$ & 2 & $\mathrm{X}$ & $\mathrm{X}$ & $1.15 \times 10^{-12}$ & 24.0 & $9: 4$ & - \\
\hline 88 & Thisbe & - & - & - & $\mathrm{X}$ & - & - & - & $\mathrm{x}$ & 2 & - & - & $5.31 \times 10^{-12}$ & 3.4 & - & $\mathrm{X}$ \\
\hline 96 & Aegle & - & - & - & - & $\mathrm{x}$ & - & - & $\mathrm{X}$ & 2 & - & - & $3.23 \times 10^{-12}$ & 29.5 & - & - \\
\hline 98 & Ianthe & - & - & - & - & - & $\mathrm{X}$ & $\mathrm{X}$ & - & 2 & - & $\mathrm{X}$ & $7.51 \times 10^{-13}$ & - & - & - \\
\hline 106 & Dione & - & - & - & - & - & $\mathrm{x}$ & $\mathrm{x}$ & - & 2 & - & - & $2.07 \times 10^{-12}$ & 48.4 & $3: 1$ & - \\
\hline 120 & Lachesis & - & - & - & - & $\mathrm{x}$ & - & $\mathrm{x}$ & - & 2 & - & - & $3.47 \times 10^{-12}$ & 12.5 & - & - \\
\hline 139 & Juewa & - & - & - & - & - & $\mathrm{x}$ & - & $\mathrm{x}$ & 2 & - & $\mathrm{x}$ & $2.53 \times 10^{-12}$ & 15.6 & - & $\mathrm{x}$ \\
\hline 216 & Kleopatra $^{\star \star}$ & - & - & - & - & - & $\mathrm{X}$ & $\mathrm{X}$ & - & 2 & - & $\mathrm{x}$ & $1.62 \times 10^{-12}$ & 32.9 & $5: 2$ & - \\
\hline 230 & Athamantis & - & - & - & - & - & $\mathrm{x}$ & $\mathrm{x}$ & - & 2 & - & $\mathrm{x}$ & $8.52 \times 10^{-13}$ & 38.6 & - & - \\
\hline 344 & Desiderata & - & $\mathrm{X}$ & - & - & - & - & $\mathrm{X}$ & - & 2 & - & $\mathrm{x}$ & $1.52 \times 10^{-12}$ & - & - & - \\
\hline 356 & Liguria & - & $\mathrm{X}$ & - & $\mathrm{X}$ & - & - & - & - & 2 & - & - & $1.49 \times 10^{-12}$ & 18.6 & - & - \\
\hline 372 & Palma & - & - & - & - & - & $\mathrm{X}$ & - & $\mathrm{X}$ & 2 & $\mathrm{x}$ & $\mathrm{x}$ & $4.41 \times 10^{-12}$ & 32.3 & $3: 1$ & - \\
\hline 405 & Thia & - & $\mathrm{X}$ & - & - & - & $\mathrm{X}$ & - & - & 2 & $\mathrm{x}$ & $\mathrm{x}$ & $1.28 \times 10^{-12}$ & 47.6 & - & - \\
\hline 409 & Aspasia & - & $\mathrm{X}$ & - & - & $\mathrm{x}$ & - & - & - & 2 & $\mathrm{X}$ & $\mathrm{x}$ & $2.78 \times 10^{-12}$ & 23.0 & $11: 5$ & $\mathrm{X}$ \\
\hline 488 & Kreusa & - & - & - & - & - & $\mathrm{x}$ & $\mathrm{x}$ & - & 2 & - & $\mathrm{x}$ & $2.23 \times 10^{-12}$ & - & $3: 1$ & - \\
\hline 554 & Peraga & - & - & - & - & - & $\mathrm{X}$ & $\mathrm{X}$ & - & 2 & - & $\mathrm{x}$ & $5.80 \times 10^{-13}$ & 10.8 & - & - \\
\hline
\end{tabular}

H.D. relates to the theoretical determination by harmonic decomposition of perturbations on the semi-major axis and the longitude of Mars period $P<50$ years, see Sect. 4.1. The three columns of $\sum \theta_{1}$ are from Table 6 which were obtained by computing the sum of the deflections of Mars over 50 years. Linear Reg. corresponds to the selection from the drift of the semi-major axis, eccentricity and inclination of Mars due to the perturbation of each asteroid - see Sect. 6. Then, we indicate if the asteroid belongs to the list of Williams (1984) and to the major perturbers of Mars in DE ephemeris. The mass $m$ is then given as well as the Gaia precision expected. The last two columns give the commensurability between the periods of Mars $P_{\mathrm{M}}$ and of asteroids $P_{\mathrm{a}}$ and the selection from secular effects on Mars - Table 5. The binary asteroids are marked by ${ }^{\star \star}$. 
Table 8. List of interesting targets for ground-based observations together with their status in the JPL list and the expected performance of Gaia to improve their mass.

\begin{tabular}{rlcc}
\hline \hline \multicolumn{2}{c}{ Asteroid } & "Major" perturbers & $\sigma(m) / m$ \\
$\mathrm{~N}^{\mathrm{o}}$ & name & JPL DE & {$[\%]$} \\
\hline 654 & Zelinda & $\checkmark$ & - \\
747 & Winchester & $\checkmark$ & 30.4 \\
105 & Artemis & $\checkmark$ & - \\
154 & Bertha & & - \\
192 & Nausikaa & $\checkmark$ & 40.9 \\
313 & Chaldaea & & - \\
63 & Ausonia & $\checkmark$ & - \\
98 & Ianthe & $\checkmark$ & - \\
106 & Dione & & 48.4 \\
216 & Kleopatra & $\checkmark$ & 32.9 \\
230 & Athamantis & $\checkmark$ & 38.6 \\
344 & Desiderata & $\checkmark$ & - \\
372 & Palma & $\checkmark$ & 32.3 \\
405 & Thia & $\checkmark$ & 47.6 \\
488 & Kreusa & $\checkmark$ & - \\
\hline
\end{tabular}

statistics portend a non-negligible contribution of Gaia in improving the modeling of perturbations by asteroids lying in the main-belt. These expected precisions were obtained from realistic simulated observation dates by Gaia from 2010.5 to 2015.5 and by investigating the close approaches between asteroids from 2010.5 to 2016 . The result are globally not very sensitive to the launch date, but are sensitive to the mission duration, which is not expected to be less than 5 years. The asteroids with an expected precision on the mass better than $10 \%$ are, in general, asteroids with a strong perturbing potential for smaller asteroids and so there will be always a large number of close approaches to be analysed. In addition, and what may be the more important argument, the contribution of ground-based observations before and after the mission to increase the masses from Gaia was investigated (Mouret 2007) giving encouraging results, and the preparation of observation campaigns concerning particular target asteroids are on-going. As a consequence, the target asteroids involved in favourable close encounters occurring before 2012 will be integrated in the preparatory ground-based observation campaigns. A large part of the information on the mass of perturbers will be preserved all the more so as the stellar catalogue issued by Gaia will increase significantly the precision of ground-based observations.

In addition, Mars' perturbers listed out of the Gaia issues, those with poor or no mass estimate expected, represent interesting targets for observations from the ground to compute or improve their mass or their volume - if no direct mass estimate is possible. They are given in Table 8 where it is specified whether the asteroid is considered as a significant perturber of Mars in the current DE planetary ephemerides and if a mass is expected to be obtained by Gaia with a precision better than $50 \%$. The asteroid (216) Kleopatra is written in italic because an accurate mass estimate is expected soon, two satellites having been observed by adaptive optics this year (Descamps 2008).

We have seen here the difficulty to objectively give a list of perturbers of Mars: we are dependent on the uncertainties on the orbital and physical characteristics of asteroids. Furthermore, the selection would change with the period of time under consideration and with the ultimate goal: improvement of the short term ephemeris (few $10 \mathrm{~s}$ of years) or the long term dynamical history of the solar system. Work is on-going to find new ways of deriving perturbers of Mars by considering the uncertainties of their orbit and mass. Thus, we will probably find potential perturbers requiring a mass estimate or improvement of their orbit to establish their real impact on the Mars orbit.

Searching for such methods of selection is all the more important as the perturbations by asteroids do not only concern Mars, but the other inner planets as well. Very precise observations of these planets will allow us to increase the accuracy of their ephemeris and, consequently, the modeling of their perturbations by asteroids will become more important. These obervations will be obtained from Venus Express (Svedhem et al. 2007) which has entered its Venusian orbit on 11 April 2006 and is delivering data, and BepiColombo (Grard et al. 2000) which will be launched in 2013 to Mercury and will reach its destination in 2018.

\section{Conclusions}

In this paper we have obtained two main results regarding the dynamical modeling of the motion of Mars:

1. Using our current knowledge of the masses and orbits of asteroids, we have produced our own list of "major" perturbers of the Martian orbit or of those which may be important, over the next 50 years. This list of 62 asteroids has been compared with the determination of the asteroid masses with the ESA astrometric mission Gaia. Of these 62, a subset of 53 masses (resp. 27) should be determined with an accuracy better than $50 \%$ (resp. 10\%). In addition, well-planned ground-based observations before and after the Gaia mission, the reduction of which will benefit from the dense and accurate Gaia stellar catalogue, should significantly augment the number of expected good mass estimates.

2. As for the perturbers with no or poor direct mass estimates in the future (14), they become obvious targets for groundbased observations to directly derive their masses or the physical properties allowing their constraint.

Acknowledgements. We thank J. G. Williams and W. M. Folkner for fruitful discussions during the preparation of this paper.

\section{References}

Albee, A. L., Arvidson, R. E., Palluconi, F., \& Thorpe, T. 2001, J. Geophys. Res., 106,23291

Baer, J., \& Chesley, S. R. 2008, Celest. Mech. Dyn. Astron., 100, 27

Bowell, E., Gehrels, T., \& Zellner, B. 1979, Magnitudes, colors, types and adopted diameters of the asteroids (Asteroids), 1108

Bowell, E., Hapke, B., Domingue, D., et al. 1989, in Asteroids II, ed. R. P. Binzel, T. Gehrels, \& M. S. Matthews, 524

Bretagnon, P. 1984, Celest. Mech., 34, 193

Britt, D. T., Yeomans, D., Housen, K., \& Consolmagno, G. 2002, in Asteroids III, ed. R. P. Binzel, W. F. Bottke, A. Cellino, \& P. Paolicchi (Tucson: University of Arizona Press), 485

Chicarro, A. F. 2006, AGU Fall Meeting Abstracts, D1

Demeo, F. E., Bus, S. J., Binzel, R. P., \& Slivan, S. M. 2008, LPI Contributions, 1405,8186

Descamps, P. 2008, personal communication

Fienga, A., Manche, H., Laskar, J., \& Gastineau, M. 2008, A\&A, 477, 315

Folkner, W. M. 2008, personal communication

Folkner, W. M., Williams, J. G., \& Boggs, D. H. 2008, IOM 343R-08-003, 31

Galád, A. 2001, A\&A, 370, 311

Goffin, E. 2001, A\&A, 365, 627

Grard, R., Novara, M., \& Scoon, G. 2000, ESA Bull., 103, 11

Hertz, H. G. 1966, IAU Circ., 1983, 3

Hilton, J. L. 2002, in Asteroids III, ed. R. P. Binzel, W. F. Bottke, A. Cellino, \& P. Paolicchi (Tucson: University of Arizona Press), 103

Konopliv, A. S., Yoder, C. F., Standish, E. M., Yuan, D.-N., \& Sjogren, W. L. 2006, Icarus, 182, 23 
Mignard, F., Cellino, A., Muinonen, K., et al. 2007, Earth Moon and Planets, 101, 97

Millis, R. L., Wasserman, L. H., Bowell, E., et al. 1981, AJ, 86, 306

Mouret, S. 2007, Ph.D. Thesis, IMCCE, Paris observatory

Mouret, S., Hestroffer, D., \& Mignard, F. 2007, A\&A, 472, 1017

Mouret, S., Hestroffer, D., \& Mignard, F. 2008, in ed. W. J. Jin, I. Platais, \& M. C. Perryman, IAU Symp., 248, in press

Pitjeva, E. V. 2005, Sol. Sys. Res., 39, 176

Russell, C. T., Capaccioni, F., Coradini, A., et al. 2006, Adv. Space Res., 38, 2043

Russell, C. T., Capaccioni, F., Coradini, A., et al. 2007, Earth Moon and Planets, 101,65

Saunders, R. S., Arvidson, R. E., Badhwar, G. D., et al. 2004, Space Sci. Rev., 110,1

Simon, J.-L. 1986, Note. Sci. Techn. Bureau Long., S013

Simon, J.-L. 1987, A\&A, 175, 303

Standish, E. M. 1998, JPL IOM, 312.F, 98
Standish, E. M., \& Fienga, A. 2002, A\&A, 384, 322

Standish, E. M., \& Hellings, R. W. 1989, Icarus, 80, 326

Standish, E. M., \& Williams, J. G. 2009, in the Explanatory Supplement to the Astronautical Almanac, Chapter8, ed. P. K. Seidelmann, U. S. Naval Observatory, Washington, D.C., in press

Standish, E. M., Newhall, X. X., Williams, J. G., \& Folkner, W. M. 1995, 10 Svedhem, H., Titov, D. V., McCoy, D., et al. 2007, Planet. Space Sci., 55, 1636

Tedesco, E. F., Noah, P. V., Noah, M., \& Price, S. D. 2004a, NASA Planetary Data System, IRAS-A-FPA-3-RDR-IMPS-V6.0, 12

Tedesco, E. T., Egan, M. P., \& Price, S. D. 2004b, NASA Planetary Data System, MSX-A-SPIRIT3-5-SBN0003-MIMPS-V1.0, 3

Tedesco, E. T., Egan, M. P., \& Price, S. D. 2004c, NASA Planetary Data System, MSX-A-SPIRIT3-5-SBN0003-MIMPS-V1.0, 3

Wasserman, L. H., Millis, R. L., Franz, O. G., et al. 1979, AJ, 84, 259

Williams, J. G. 1984, Icarus, 57, 1

Williams, J. G. 2008, personal communication. 
S. Mouret et al.: The list of asteroids perturbing the Mars orbit to be seen during future space missions, Online Material $p 1$

\section{Appendix A: Theoretical perturbations of asteroids on Mars}

Table A.1. Theoretical perturbations of asteroids with periods shorter than 50 years on the orbital semi-major axis and mean longitude of Mars to the first order in mass.

\begin{tabular}{|c|c|c|c|c|c|c|c|c|c|}
\hline \multirow{3}{*}{$\mathrm{N}^{\mathrm{o}}$} & steroid & \multicolumn{4}{|c|}{ Semi-major axis of Mars } & \multicolumn{4}{|c|}{ Mean longitude of Mars } \\
\hline & name & \multicolumn{2}{|c|}{$\underset{i \bar{\lambda}_{\mathrm{M}}+j \bar{\lambda}_{\mathrm{c}}}{\text { Argument }}$} & \multirow{2}{*}{$\begin{array}{c}\text { Amplitude } \\
c_{i j} \\
{[\mathrm{AU}]}\end{array}$} & \multirow{2}{*}{$\begin{array}{c}\text { Period } \\
P_{i j} \\
\text { [years] }\end{array}$} & \multicolumn{2}{|c|}{$\begin{array}{l}\text { Argumen } \\
i \bar{\lambda}_{\mathrm{M}}+j \bar{\lambda}\end{array}$} & \multirow{2}{*}{$\begin{array}{c}\text { Amplitude } \\
c_{i j} \\
\text { [radian] }\end{array}$} & \multirow{2}{*}{$\begin{array}{c}\text { Period } \\
P_{i j} \\
\text { [years] }\end{array}$} \\
\hline & & & $j$ & & & $i$ & $j$ & & \\
\hline \multirow[t]{44}{*}{1} & \multirow[t]{44}{*}{ Ceres } & 2 & -5 & $4.05 \times 10^{-10}$ & 45.77 & 2 & -5 & $9.28 \times 10^{-09}$ & 45.77 \\
\hline & & 1 & -2 & $3.97 \times 10^{-10}$ & 10.25 & 1 & -2 & $2.77 \times 10^{-09}$ & 10.25 \\
\hline & & 2 & -2 & $3.31 \times 10^{-10}$ & 1.59 & 2 & -4 & $6.15 \times 10^{-10}$ & 5.12 \\
\hline & & 2 & -3 & $2.43 \times 10^{-10}$ & 2.43 & 2 & -2 & $5.27 \times 10^{-10}$ & 1.59 \\
\hline & & 2 & -4 & $1.68 \times 10^{-10}$ & 5.12 & 2 & -3 & $5.25 \times 10^{-10}$ & 2.43 \\
\hline & & 3 & -3 & $1.33 \times 10^{-10}$ & 1.06 & 1 & -1 & $3.92 \times 10^{-10}$ & 3.18 \\
\hline & & 3 & -4 & $1.24 \times 10^{-10}$ & 1.38 & 3 & -7 & $3.92 \times 10^{-10}$ & 13.20 \\
\hline & & 1 & -3 & $1.05 \times 10^{-10}$ & 8.37 & 1 & -3 & $2.92 \times 10^{-10}$ & 8.37 \\
\hline & & 1 & -1 & $9.96 \times 10^{-11}$ & 3.18 & 3 & -4 & $1.90 \times 10^{-10}$ & 1.38 \\
\hline & & 3 & -5 & $7.60 \times 10^{-11}$ & 1.96 & 3 & -3 & $1.73 \times 10^{-10}$ & 1.06 \\
\hline & & 4 & -5 & $6.48 \times 10^{-11}$ & 0.96 & 0 & 1 & $1.55 \times 10^{-10}$ & 4.61 \\
\hline & & 4 & -4 & $5.31 \times 10^{-11}$ & 0.79 & 3 & -5 & $1.44 \times 10^{-10}$ & 1.96 \\
\hline & & 3 & -7 & $4.99 \times 10^{-11}$ & 13.20 & 3 & -6 & $1.21 \times 10^{-10}$ & 3.42 \\
\hline & & 3 & -6 & $4.46 \times 10^{-11}$ & 3.42 & 4 & -10 & $1.06 \times 10^{-10}$ & 22.88 \\
\hline & & 4 & -6 & $4.43 \times 10^{-11}$ & 1.21 & & & & \\
\hline & & 5 & -6 & $3.31 \times 10^{-11}$ & 0.74 & & & & \\
\hline & & 3 & -2 & $3.13 \times 10^{-11}$ & 0.86 & & & & \\
\hline & & 5 & -7 & $2.63 \times 10^{-11}$ & 0.88 & & & & \\
\hline & & 4 & -7 & $2.45 \times 10^{-11}$ & 1.65 & & & & \\
\hline & & 4 & -3 & $2.25 \times 10^{-11}$ & 0.68 & & & & \\
\hline & & 1 & 0 & $2.00 \times 10^{-11}$ & 1.88 & & & & \\
\hline & & 5 & -5 & $1.98 \times 10^{-11}$ & 0.64 & & & & \\
\hline & & 6 & -7 & $1.62 \times 10^{-11}$ & 0.60 & & & & \\
\hline & & 5 & -8 & $1.56 \times 10^{-11}$ & 1.08 & & & & \\
\hline & & 6 & -8 & $1.52 \times 10^{-11}$ & 0.69 & & & & \\
\hline & & 5 & -4 & $1.41 \times 10^{-11}$ & 0.56 & & & & \\
\hline & & 4 & -8 & $1.30 \times 10^{-11}$ & 2.56 & & & & \\
\hline & & 6 & -9 & $1.00 \times 10^{-11}$ & 0.81 & & & & \\
\hline & & 4 & -10 & $9.60 \times 10^{-12}$ & 22.88 & & & & \\
\hline & & 2 & -6 & $8.87 \times 10^{-12}$ & 4.19 & & & & \\
\hline & & 1 & -4 & $8.86 \times 10^{-12}$ & 2.97 & & & & \\
\hline & & 4 & -9 & $8.81 \times 10^{-12}$ & 5.77 & & & & \\
\hline & & 7 & -9 & $8.52 \times 10^{-12}$ & 0.57 & & & & \\
\hline & & 6 & -5 & $8.10 \times 10^{-12}$ & 0.48 & & & & \\
\hline & & 5 & -9 & $8.04 \times 10^{-12}$ & 1.42 & & & & \\
\hline & & 7 & -8 & $7.58 \times 10^{-12}$ & 0.50 & & & & \\
\hline & & 3 & -8 & $6.97 \times 10^{-12}$ & 7.08 & & & & \\
\hline & & 6 & -6 & $6.41 \times 10^{-12}$ & 0.53 & & & & \\
\hline & & 7 & -10 & $6.30 \times 10^{-12}$ & 0.64 & & & & \\
\hline & & 6 & -10 & $5.47 \times 10^{-12}$ & 0.98 & & & & \\
\hline & & 8 & -10 & $4.59 \times 10^{-12}$ & 0.48 & & & & \\
\hline & & 2 & 0 & $4.36 \times 10^{-12}$ & 0.94 & & & & \\
\hline & & 7 & -6 & $4.33 \times 10^{-12}$ & 0.41 & & & & \\
\hline & & 2 & -1 & $4.23 \times 10^{-12}$ & 1.18 & & & & \\
\hline \multirow[t]{9}{*}{2} & \multirow[t]{9}{*}{ Pallas } & 2 & -5 & $4.97 \times 10^{-10}$ & 48.65 & 2 & -5 & $1.23 \times 10^{-08}$ & 48.65 \\
\hline & & 3 & -7 & $9.86 \times 10^{-11}$ & 12.89 & 4 & -10 & $1.10 \times 10^{-09}$ & 24.32 \\
\hline & & 4 & -10 & $9.28 \times 10^{-11}$ & 24.32 & 3 & -7 & $7.44 \times 10^{-10}$ & 12.89 \\
\hline & & 2 & -4 & $8.84 \times 10^{-11}$ & 5.10 & 5 & -12 & $4.78 \times 10^{-10}$ & 17.54 \\
\hline & & 2 & -3 & $6.43 \times 10^{-11}$ & 2.42 & 7 & -17 & $4.04 \times 10^{-10}$ & 27.44 \\
\hline & & 5 & -12 & $4.76 \times 10^{-11}$ & 17.54 & 2 & -4 & $2.96 \times 10^{-10}$ & 5.10 \\
\hline & & 2 & -2 & $4.37 \times 10^{-11}$ & 1.59 & 1 & -2 & $2.73 \times 10^{-10}$ & 10.19 \\
\hline & & 1 & -2 & $4.35 \times 10^{-11}$ & 10.19 & 6 & -15 & $1.71 \times 10^{-10}$ & 16.22 \\
\hline & & 1 & -3 & $4.25 \times 10^{-11}$ & 8.43 & 1 & -3 & $1.28 \times 10^{-10}$ & 8.43 \\
\hline
\end{tabular}


S. Mouret et al.: The list of asteroids perturbing the Mars orbit to be seen during future space missions, Online Material $p 2$

Table A.1. continued.

\begin{tabular}{|c|c|c|c|c|c|c|c|c|c|}
\hline \multicolumn{2}{|r|}{ Asteroid } & \multicolumn{4}{|c|}{$\overline{\text { Semi-major axis of Mars }}$} & \multicolumn{4}{|c|}{ Mean longitude of Mars } \\
\hline \multirow[t]{2}{*}{$\mathrm{N}^{\mathrm{o}}$} & \multirow[t]{2}{*}{ name } & \multicolumn{2}{|c|}{$\begin{array}{c}\text { Argument } \\
i \bar{\lambda}_{\mathrm{M}}+j \bar{\lambda}_{\mathrm{c}}\end{array}$} & \multirow{2}{*}{$\begin{array}{c}\text { Amplitude } \\
c_{i j} \\
{[\mathrm{AU}]}\end{array}$} & \multirow{2}{*}{$\begin{array}{c}\text { Period } \\
P_{i j} \\
\text { [years] }\end{array}$} & \multicolumn{2}{|c|}{$\begin{array}{l}\text { Argument } \\
i \bar{\lambda}_{\mathrm{M}}+j \bar{\lambda}_{\mathrm{c}}\end{array}$} & \multirow{2}{*}{$\begin{array}{c}\text { Amplitude } \\
c_{i j} \\
\text { [radian] }\end{array}$} & \multirow{2}{*}{$\begin{array}{c}\text { Period } \\
P_{i j} \\
\text { [years] }\end{array}$} \\
\hline & & $i$ & $j$ & & & $i$ & $j$ & & \\
\hline & & 3 & -6 & $3.87 \times 10^{-11}$ & 3.40 & 2 & -3 & $1.24 \times 10^{-10}$ & 2.42 \\
\hline & & 3 & -8 & $3.68 \times 10^{-11}$ & 7.18 & 4 & -9 & $1.16 \times 10^{-10}$ & 5.69 \\
\hline & & 3 & -5 & $3.10 \times 10^{-11}$ & 1.96 & 3 & -8 & $1.05 \times 10^{-10}$ & 7.18 \\
\hline & & 4 & -9 & $3.07 \times 10^{-11}$ & 5.69 & 3 & -6 & $9.60 \times 10^{-11}$ & 3.40 \\
\hline & & 7 & -17 & $2.65 \times 10^{-11}$ & 27.44 & & & & \\
\hline & & 2 & -6 & $2.63 \times 10^{-11}$ & 4.21 & & & & \\
\hline & & 3 & -4 & $2.40 \times 10^{-11}$ & 1.37 & & & & \\
\hline & & 6 & -15 & $2.25 \times 10^{-11}$ & 16.22 & & & & \\
\hline & & 4 & -8 & $1.91 \times 10^{-11}$ & 2.55 & & & & \\
\hline & & 4 & -7 & $1.62 \times 10^{-11}$ & 1.64 & & & & \\
\hline & & 1 & -4 & $1.38 \times 10^{-11}$ & 2.98 & & & & \\
\hline & & 4 & -6 & $1.36 \times 10^{-11}$ & 1.21 & & & & \\
\hline & & 5 & -11 & $1.35 \times 10^{-11}$ & 3.65 & & & & \\
\hline & & 5 & -13 & $1.23 \times 10^{-11}$ & 6.26 & & & & \\
\hline & & 6 & -14 & $1.21 \times 10^{-11}$ & 6.45 & & & & \\
\hline & & 2 & 0 & $1.17 \times 10^{-11}$ & 0.94 & & & & \\
\hline & & 3 & -3 & $1.09 \times 10^{-11}$ & 1.06 & & & & \\
\hline & & 2 & -1 & $1.04 \times 10^{-11}$ & 1.18 & & & & \\
\hline & & 4 & -11 & $1.04 \times 10^{-11}$ & 3.88 & & & & \\
\hline & & 3 & -2 & $1.01 \times 10^{-11}$ & 0.86 & & & & \\
\hline & & 5 & -10 & $1.00 \times 10^{-11}$ & 2.04 & & & & \\
\hline & & 3 & -9 & $9.70 \times 10^{-12}$ & 2.81 & & & & \\
\hline & & 4 & -5 & $9.03 \times 10^{-12}$ & 0.96 & & & & \\
\hline & & 5 & -9 & $8.82 \times 10^{-12}$ & 1.41 & & & & \\
\hline & & 2 & -7 & $8.77 \times 10^{-12}$ & 2.20 & & & & \\
\hline & & 5 & -8 & $7.78 \times 10^{-12}$ & 1.08 & & & & \\
\hline & & 3 & -1 & $7.51 \times 10^{-12}$ & 0.73 & & & & \\
\hline & & 6 & -13 & $6.69 \times 10^{-12}$ & 2.69 & & & & \\
\hline & & 4 & -3 & $6.66 \times 10^{-12}$ & 0.68 & & & & \\
\hline & & 1 & -5 & $6.25 \times 10^{-12}$ & 1.81 & & & & \\
\hline & & 8 & -20 & $6.09 \times 10^{-12}$ & 12.16 & & & & \\
\hline & & 5 & -7 & $6.04 \times 10^{-12}$ & 0.88 & & & & \\
\hline & & 1 & 0 & $5.71 \times 10^{-12}$ & 1.88 & & & & \\
\hline & & 1 & 1 & $5.63 \times 10^{-12}$ & 1.34 & & & & \\
\hline & & 6 & -12 & $5.47 \times 10^{-12}$ & 1.70 & & & & \\
\hline & & 7 & -16 & $5.05 \times 10^{-12}$ & 3.95 & & & & \\
\hline & & 1 & -1 & $4.97 \times 10^{-12}$ & 3.18 & & & & \\
\hline & & 6 & -11 & $4.96 \times 10^{-12}$ & 1.24 & & & & \\
\hline & & 8 & -19 & $4.92 \times 10^{-12}$ & 7.43 & & & & \\
\hline & & 4 & -4 & $4.75 \times 10^{-12}$ & 0.79 & & & & \\
\hline & & 6 & -10 & $4.51 \times 10^{-12}$ & 0.98 & & & & \\
\hline & & 2 & 1 & $4.43 \times 10^{-12}$ & 0.78 & & & & \\
\hline & & 3 & -10 & $4.05 \times 10^{-12}$ & 1.75 & & & & \\
\hline \multirow[t]{18}{*}{4} & Vesta & 2 & -4 & $2.59 \times 10^{-10}$ & 25.93 & 2 & -4 & $3.24 \times 10^{-09}$ & 25.93 \\
\hline & & 2 & -2 & $2.03 \times 10^{-10}$ & 1.95 & 2 & -3 & $5.34 \times 10^{-10}$ & 4.22 \\
\hline & & 2 & -3 & $1.67 \times 10^{-10}$ & 4.22 & 3 & -6 & $4.99 \times 10^{-10}$ & 17.29 \\
\hline & & 3 & -3 & $1.05 \times 10^{-10}$ & 1.30 & 2 & -2 & $3.78 \times 10^{-10}$ & 1.95 \\
\hline & & 3 & -4 & $8.86 \times 10^{-11}$ & 2.03 & 1 & -1 & $3.41 \times 10^{-10}$ & 3.90 \\
\hline & & 1 & -1 & $7.57 \times 10^{-11}$ & 3.90 & 3 & -5 & $2.18 \times 10^{-10}$ & 4.59 \\
\hline & & 3 & -5 & $6.57 \times 10^{-11}$ & 4.59 & 3 & -4 & $1.70 \times 10^{-10}$ & 2.03 \\
\hline & & 3 & -6 & $6.11 \times 10^{-11}$ & 17.29 & 3 & -3 & $1.53 \times 10^{-10}$ & 1.30 \\
\hline & & 4 & -4 & $5.48 \times 10^{-11}$ & 0.98 & & & & \\
\hline & & 4 & -5 & $5.40 \times 10^{-11}$ & 1.33 & & & & \\
\hline & & 4 & -6 & $3.47 \times 10^{-11}$ & 2.11 & & & & \\
\hline & & 5 & -6 & $3.37 \times 10^{-11}$ & 0.99 & & & & \\
\hline & & 5 & -5 & $2.87 \times 10^{-11}$ & 0.78 & & & & \\
\hline & & 4 & -7 & $2.49 \times 10^{-11}$ & 5.04 & & & & \\
\hline & & 5 & -7 & $2.27 \times 10^{-11}$ & 1.37 & & & & \\
\hline & & 6 & -7 & $2.10 \times 10^{-11}$ & 0.79 & & & & \\
\hline & & 1 & -3 & $1.56 \times 10^{-11}$ & 3.39 & & & & \\
\hline & & 6 & -8 & $1.55 \times 10^{-11}$ & 1.01 & & & & \\
\hline
\end{tabular}


S. Mouret et al.: The list of asteroids perturbing the Mars orbit to be seen during future space missions, Online Material p 3

Table A.1. continued.

\begin{tabular}{|c|c|c|c|c|c|c|c|c|c|}
\hline \multicolumn{2}{|c|}{ Asteroid } & \multicolumn{4}{|c|}{ Semi-major axis of Mars } & \multicolumn{4}{|c|}{ Mean longitude of Mars } \\
\hline $\mathrm{N}^{\mathrm{o}}$ & name & $\begin{array}{l}\mathrm{A} \\
i \bar{\lambda} \\
i\end{array}$ & $\begin{array}{l}\text { ment } \\
+j \bar{\lambda}_{\mathrm{c}} \\
j\end{array}$ & $\begin{array}{c}\text { Amplitude } \\
c_{i j} \\
{[\mathrm{AU}]}\end{array}$ & $\begin{array}{c}\text { Period } \\
P_{i j} \\
\text { [years] }\end{array}$ & & $\begin{array}{l}\operatorname{men} \\
+j \bar{\lambda} \\
j\end{array}$ & $\begin{array}{c}\text { Amplitude } \\
c_{i j} \\
\text { [radian] }\end{array}$ & $\begin{array}{c}\text { Period } \\
P_{i j} \\
\text { [years] }\end{array}$ \\
\hline & & 4 & -8 & $1.53 \times 10^{-11}$ & 12.97 & & & & \\
\hline & & 6 & -6 & $1.48 \times 10^{-11}$ & 0.65 & & & & \\
\hline & & 5 & -8 & $1.29 \times 10^{-11}$ & 2.20 & & & & \\
\hline & & 7 & -8 & $1.29 \times 10^{-11}$ & 0.66 & & & & \\
\hline & & 3 & -2 & $1.15 \times 10^{-11}$ & 0.96 & & & & \\
\hline & & 4 & -3 & $1.10 \times 10^{-11}$ & 0.77 & & & & \\
\hline & & 7 & -9 & $1.06 \times 10^{-11}$ & 0.80 & & & & \\
\hline & & 5 & -9 & $9.24 \times 10^{-12}$ & 5.58 & & & & \\
\hline & & 1 & 0 & $9.14 \times 10^{-12}$ & 1.88 & & & & \\
\hline & & 5 & -4 & $8.85 \times 10^{-12}$ & 0.64 & & & & \\
\hline & & 6 & -9 & $8.81 \times 10^{-12}$ & 1.41 & & & & \\
\hline & & 8 & -9 & $7.83 \times 10^{-12}$ & 0.56 & & & & \\
\hline & & 7 & -7 & $7.47 \times 10^{-12}$ & 0.56 & & & & \\
\hline & & 8 & -10 & $7.20 \times 10^{-12}$ & 0.67 & & & & \\
\hline & & 6 & -5 & $6.55 \times 10^{-12}$ & 0.55 & & & & \\
\hline & & 7 & -10 & $6.36 \times 10^{-12}$ & 1.03 & & & & \\
\hline & & 2 & -5 & $6.14 \times 10^{-12}$ & 3.18 & & & & \\
\hline & & 2 & -1 & $5.25 \times 10^{-12}$ & 1.27 & & & & \\
\hline & & 9 & -11 & $4.82 \times 10^{-12}$ & 0.57 & & & & \\
\hline & & 9 & -10 & $4.66 \times 10^{-12}$ & 0.49 & & & & \\
\hline & & 6 & -10 & $4.65 \times 10^{-12}$ & 2.30 & & & & \\
\hline & & 8 & -11 & $4.64 \times 10^{-12}$ & 0.82 & & & & \\
\hline & & 7 & -6 & $4.60 \times 10^{-12}$ & 0.48 & & & & \\
\hline 7 & Iris & 2 & -4 & $9.69 \times 10^{-11}$ & 46.45 & 2 & -4 & $2.25 \times 10^{-09}$ & 46.45 \\
\hline & & 3 & -6 & $5.19 \times 10^{-11}$ & 30.97 & 3 & -6 & $7.91 \times 10^{-10}$ & 30.97 \\
\hline & & 4 & -8 & $3.00 \times 10^{-11}$ & 23.23 & 4 & -8 & $3.38 \times 10^{-10}$ & 23.23 \\
\hline & & 5 & -10 & $1.83 \times 10^{-11}$ & 18.58 & 5 & -10 & $1.62 \times 10^{-10}$ & 18.58 \\
\hline & & 2 & -3 & $1.46 \times 10^{-11}$ & 4.00 & & & & \\
\hline & & 3 & -5 & $1.16 \times 10^{-11}$ & 4.19 & & & & \\
\hline & & 6 & -12 & $1.15 \times 10^{-11}$ & 15.48 & & & & \\
\hline & & 4 & -7 & $9.10 \times 10^{-12}$ & 4.38 & & & & \\
\hline & & 2 & -2 & $8.60 \times 10^{-12}$ & 1.92 & & & & \\
\hline & & 7 & -14 & $7.42 \times 10^{-12}$ & 13.27 & & & & \\
\hline & & 3 & -4 & $7.33 \times 10^{-12}$ & 1.96 & & & & \\
\hline & & 5 & -9 & $7.14 \times 10^{-12}$ & 4.60 & & & & \\
\hline & & 4 & -6 & $5.79 \times 10^{-12}$ & 2.00 & & & & \\
\hline & & 6 & -11 & $5.60 \times 10^{-12}$ & 4.84 & & & & \\
\hline & & 8 & -16 & $4.87 \times 10^{-12}$ & 11.61 & & & & \\
\hline & & 5 & -8 & $4.49 \times 10^{-12}$ & 2.05 & & & & \\
\hline & & 7 & -13 & $4.40 \times 10^{-12}$ & 5.11 & & & & \\
\hline & & 4 & -5 & $4.06 \times 10^{-12}$ & 1.30 & & & & \\
\hline 3 & Juno & 2 & -4 & $2.46 \times 10^{-11}$ & 6.79 & 1 & -2 & $1.37 \times 10^{-10}$ & 13.59 \\
\hline & & 2 & -5 & $2.20 \times 10^{-11}$ & 12.22 & 4 & -9 & $1.31 \times 10^{-10}$ & 15.30 \\
\hline & & 2 & -3 & $1.56 \times 10^{-11}$ & 2.66 & 2 & -5 & $1.26 \times 10^{-10}$ & 12.22 \\
\hline & & 1 & -2 & $1.56 \times 10^{-11}$ & 13.59 & 2 & -4 & $1.06 \times 10^{-10}$ & 6.79 \\
\hline & & 4 & -9 & $1.53 \times 10^{-11}$ & 15.30 & & & & \\
\hline & & 3 & -6 & $1.19 \times 10^{-11}$ & 4.53 & & & & \\
\hline & & 2 & -2 & $1.03 \times 10^{-11}$ & 1.65 & & & & \\
\hline & & 3 & -5 & $9.13 \times 10^{-12}$ & 2.22 & & & & \\
\hline & & 3 & -4 & $7.19 \times 10^{-12}$ & 1.47 & & & & \\
\hline & & 4 & -8 & $6.16 \times 10^{-12}$ & 3.40 & & & & \\
\hline & & 4 & -7 & $5.35 \times 10^{-12}$ & 1.91 & & & & \\
\hline & & 1 & -3 & $5.09 \times 10^{-12}$ & 6.43 & & & & \\
\hline & & 5 & -11 & $5.00 \times 10^{-12}$ & 7.20 & & & & \\
\hline & & 4 & -6 & $4.67 \times 10^{-12}$ & 1.33 & & & & \\
\hline 15 & Eunomia & 2 & -4 & $1.38 \times 10^{-11}$ & 7.55 & 3 & -7 & $1.53 \times 10^{-10}$ & 29.28 \\
\hline
\end{tabular}


S. Mouret et al.: The list of asteroids perturbing the Mars orbit to be seen during future space missions, Online Material p 4

Table A.1. continued.

\begin{tabular}{|c|c|c|c|c|c|c|c|c|c|}
\hline \multicolumn{2}{|c|}{ Asteroid } & \multicolumn{4}{|c|}{ Semi-major axis of Mars } & \multicolumn{4}{|c|}{ Mean longitude of Mars } \\
\hline \multirow[t]{2}{*}{$\mathrm{N}^{\mathrm{o}}$} & \multirow[t]{2}{*}{ name } & \multicolumn{2}{|c|}{$\begin{array}{l}\text { Argument } \\
i \bar{\lambda}_{\mathrm{M}}+j \bar{\lambda}_{\mathrm{c}}\end{array}$} & \multirow{2}{*}{$\begin{array}{c}\text { Amplitude } \\
c_{i j} \\
{[\mathrm{AU}]}\end{array}$} & \multirow{2}{*}{$\begin{array}{l}\text { Period } \\
P_{i j} \\
\text { [years] }\end{array}$} & \multicolumn{2}{|c|}{$\begin{array}{l}\text { Argument } \\
i \bar{\lambda}_{\mathrm{M}}+j \bar{\lambda}_{\mathrm{c}}\end{array}$} & \multirow{2}{*}{$\begin{array}{c}\text { Amplitude } \\
c_{i j} \\
\text { [radian] }\end{array}$} & \multirow{2}{*}{$\begin{array}{c}\text { Period } \\
P_{i j} \\
\text { [years] }\end{array}$} \\
\hline & & $i$ & $j$ & & & $i$ & $j$ & & \\
\hline & & 1 & -2 & $1.38 \times 10^{-11}$ & 15.11 & 1 & -2 & $1.31 \times 10^{-10}$ & 15.11 \\
\hline & & 2 & -2 & $1.26 \times 10^{-11}$ & 1.67 & 4 & -9 & $1.04 \times 10^{-10}$ & 31.21 \\
\hline & & 2 & -3 & $1.25 \times 10^{-11}$ & 2.74 & & & & \\
\hline & & 3 & -7 & $1.05 \times 10^{-11}$ & 29.28 & & & & \\
\hline & & 3 & -4 & $6.60 \times 10^{-12}$ & 1.51 & & & & \\
\hline & & 2 & -5 & $6.19 \times 10^{-12}$ & 9.96 & & & & \\
\hline & & 4 & -9 & $6.10 \times 10^{-12}$ & 31.21 & & & & \\
\hline & & 3 & -3 & $5.62 \times 10^{-12}$ & 1.12 & & & & \\
\hline & & 3 & -5 & $5.35 \times 10^{-12}$ & 2.32 & & & & \\
\hline & & 3 & -6 & $4.85 \times 10^{-12}$ & 5.04 & & & & \\
\hline & & 1 & -1 & $4.14 \times 10^{-12}$ & 3.35 & & & & \\
\hline \multirow[t]{10}{*}{654} & Zelinda & 6 & -11 & $1.30 \times 10^{-11}$ & 32.06 & 6 & -11 & $2.26 \times 10^{-10}$ & 32.06 \\
\hline & & 2 & -4 & $7.12 \times 10^{-12}$ & 11.72 & 14 & -26 & $1.07 \times 10^{-10}$ & 43.59 \\
\hline & & 5 & -9 & $6.57 \times 10^{-12}$ & 13.54 & & & & \\
\hline & & 8 & -15 & $5.22 \times 10^{-12}$ & 18.47 & & & & \\
\hline & & 4 & -7 & $5.01 \times 10^{-12}$ & 8.58 & & & & \\
\hline & & 14 & -26 & $4.83 \times 10^{-12}$ & 43.59 & & & & \\
\hline & & 1 & -2 & $4.75 \times 10^{-12}$ & 23.44 & & & & \\
\hline & & 3 & -5 & $4.42 \times 10^{-12}$ & 6.28 & & & & \\
\hline & & 2 & -3 & $4.25 \times 10^{-12}$ & 4.95 & & & & \\
\hline & & 3 & -6 & $4.18 \times 10^{-12}$ & 7.81 & & & & \\
\hline \multirow[t]{9}{*}{324} & Bamberga & 2 & -5 & $1.51 \times 10^{-11}$ & 13.80 & 2 & -5 & $9.77 \times 10^{-11}$ & 13.80 \\
\hline & & 2 & -4 & $1.16 \times 10^{-11}$ & 6.46 & & & & \\
\hline & & 4 & -9 & $1.06 \times 10^{-11}$ & 12.16 & & & & \\
\hline & & 5 & -12 & $7.01 \times 10^{-12}$ & 14.80 & & & & \\
\hline & & 3 & -6 & $6.67 \times 10^{-12}$ & 4.31 & & & & \\
\hline & & 2 & -3 & $6.37 \times 10^{-12}$ & 2.62 & & & & \\
\hline & & 5 & -11 & $4.53 \times 10^{-12}$ & 6.27 & & & & \\
\hline & & 3 & -5 & $4.39 \times 10^{-12}$ & 2.18 & & & & \\
\hline & & 4 & -8 & $4.08 \times 10^{-12}$ & 3.23 & & & & \\
\hline \multirow[t]{6}{*}{19} & Fortuna & 3 & -6 & $1.75 \times 10^{-11}$ & 43.02 & 3 & -6 & $4.09 \times 10^{-10}$ & 43.02 \\
\hline & & 2 & -2 & $8.12 \times 10^{-12}$ & 1.85 & 4 & -8 & $1.15 \times 10^{-10}$ & 32.26 \\
\hline & & 2 & -3 & $8.02 \times 10^{-12}$ & 3.60 & & & & \\
\hline & & 4 & -8 & $6.50 \times 10^{-12}$ & 32.26 & & & & \\
\hline & & 3 & -4 & $4.38 \times 10^{-12}$ & 1.83 & & & & \\
\hline & & 3 & -3 & $4.08 \times 10^{-12}$ & 1.24 & & & & \\
\hline \multirow[t]{7}{*}{10} & Hygiea & 2 & -2 & $1.86 \times 10^{-11}$ & 1.42 & & & & \\
\hline & & 1 & -2 & $1.24 \times 10^{-11}$ & 5.82 & & & & \\
\hline & & 2 & -3 & $1.21 \times 10^{-11}$ & 1.91 & & & & \\
\hline & & 3 & -3 & $6.85 \times 10^{-12}$ & 0.95 & & & & \\
\hline & & 2 & -4 & $6.20 \times 10^{-12}$ & 2.91 & & & & \\
\hline & & 3 & -4 & $5.88 \times 10^{-12}$ & 1.14 & & & & \\
\hline & & 1 & -1 & $5.24 \times 10^{-12}$ & 2.84 & & & & \\
\hline 41 & Daphne & 2 & -5 & $2.52 \times 10^{-11}$ & 37.28 & 2 & -5 & $4.69 \times 10^{-10}$ & 37.28 \\
\hline
\end{tabular}


S. Mouret et al.: The list of asteroids perturbing the Mars orbit to be seen during future space missions, Online Material p 5

Table A.1. continued.

\begin{tabular}{|c|c|c|c|c|c|c|c|c|c|}
\hline \multicolumn{2}{|c|}{ Asteroid } & \multicolumn{4}{|c|}{$\overline{\text { Semi-major axis of Mars }}$} & \multicolumn{4}{|c|}{ Mean longitude of Mars } \\
\hline \multirow[t]{5}{*}{$\mathrm{N}^{\mathrm{o}}$} & name & \multicolumn{2}{|c|}{$\begin{array}{l}\text { Argument } \\
i \bar{\lambda}_{\mathrm{M}}+j \bar{\lambda}_{\mathrm{c}}\end{array}$} & $\begin{array}{c}\text { Amplitude } \\
c_{i j} \\
{[\mathrm{AU}]}\end{array}$ & $\begin{array}{c}\text { Period } \\
P_{i j} \\
\text { [years] }\end{array}$ & \multicolumn{2}{|c|}{$\begin{array}{l}\text { Argument } \\
i \bar{\lambda}_{\mathrm{M}}+j \bar{\lambda}_{\mathrm{c}}\end{array}$} & $\begin{array}{c}\text { Amplitude } \\
c_{i j} \\
\text { [radian] }\end{array}$ & $\begin{array}{c}\text { Period } \\
P_{i j} \\
\text { [years] }\end{array}$ \\
\hline & & 3 & -7 & $8.84 \times 10^{-12}$ & 14.54 & 5 & -12 & $9.75 \times 10^{-11}$ & 23.83 \\
\hline & & 5 & -12 & $7.32 \times 10^{-12}$ & 23.83 & & & & \\
\hline & & 4 & -10 & $6.80 \times 10^{-12}$ & 18.64 & & & & \\
\hline & & 2 & -4 & $5.40 \times 10^{-12}$ & 5.23 & & & & \\
\hline \multirow[t]{6}{*}{532} & Herculina 2 & & -5 & $2.72 \times 10^{-11}$ & 47.68 & 2 & -5 & $6.56 \times 10^{-10}$ & 47.68 \\
\hline & & 2 & -4 & $6.39 \times 10^{-12}$ & 5.10 & & & & \\
\hline & & 1 & -2 & $6.32 \times 10^{-12}$ & 10.21 & & & & \\
\hline & & 2 & -3 & $5.51 \times 10^{-12}$ & 2.42 & & & & \\
\hline & & 3 & -7 & $5.00 \times 10^{-12}$ & 12.99 & & & & \\
\hline & & 2 & -2 & $4.39 \times 10^{-12}$ & 1.59 & & & & \\
\hline \multirow[t]{3}{*}{9} & Metis & 2 & -4 & $1.82 \times 10^{-11}$ & 45.61 & 2 & -4 & $4.14 \times 10^{-10}$ & 45.61 \\
\hline & & 3 & -6 & $6.85 \times 10^{-12}$ & 30.41 & 3 & -6 & $1.02 \times 10^{-10}$ & 30.41 \\
\hline & & 2 & -3 & $4.07 \times 10^{-12}$ & 4.01 & & & & \\
\hline \multirow[t]{4}{*}{13} & Egeria & 1 & -2 & $1.13 \times 10^{-11}$ & 20.59 & 1 & -2 & $1.38 \times 10^{-10}$ & 20.59 \\
\hline & & 2 & -2 & $5.27 \times 10^{-12}$ & 1.72 & & & & \\
\hline & & 2 & -4 & $4.53 \times 10^{-12}$ & 10.30 & & & & \\
\hline & & 2 & -3 & $4.46 \times 10^{-12}$ & 2.95 & & & & \\
\hline \multirow[t]{3}{*}{344} & Desiderata & 4 & -9 & $9.08 \times 10^{-12}$ & 38.55 & 4 & -9 & $1.77 \times 10^{-10}$ & 38.55 \\
\hline & & 5 & -11 & $7.13 \times 10^{-12}$ & 36.54 & 5 & -11 & $1.41 \times 10^{-10}$ & 36.54 \\
\hline & & 2 & -4 & $4.63 \times 10^{-12}$ & 9.38 & & & & \\
\hline \multirow[t]{5}{*}{511} & Davida & 2 & -2 & $8.06 \times 10^{-12}$ & 1.41 & & & & \\
\hline & & 2 & -3 & $8.01 \times 10^{-12}$ & 1.89 & & & & \\
\hline & & 2 & -4 & $6.43 \times 10^{-12}$ & 2.84 & & & & \\
\hline & & 2 & -5 & $6.14 \times 10^{-12}$ & 5.72 & & & & \\
\hline & & 1 & -2 & $5.92 \times 10^{-12}$ & 5.67 & & & & \\
\hline \multirow[t]{4}{*}{6} & Hebe & 2 & -3 & $8.85 \times 10^{-12}$ & 3.72 & & & & \\
\hline & & 2 & -2 & $7.41 \times 10^{-12}$ & 1.87 & & & & \\
\hline & & 3 & -4 & $4.62 \times 10^{-12}$ & 1.87 & & & & \\
\hline & & 3 & -5 & $4.56 \times 10^{-12}$ & 3.69 & & & & \\
\hline \multirow[t]{3}{*}{704} & Interamnia & 1 & -3 & $1.43 \times 10^{-11}$ & 34.57 & 1 & -3 & $2.37 \times 10^{-10}$ & 34.57 \\
\hline & & 2 & -2 & $7.79 \times 10^{-12}$ & 1.45 & & & & \\
\hline & & 2 & -3 & $4.66 \times 10^{-12}$ & 1.99 & & & & \\
\hline \multirow[t]{3}{*}{18} & Melpomene & 2 & -4 & $4.77 \times 10^{-12}$ & 11.58 & & & & \\
\hline & & 6 & -11 & $4.72 \times 10^{-12}$ & 35.15 & & & & \\
\hline & & 2 & -3 & $4.67 \times 10^{-12}$ & 4.97 & & & & \\
\hline \multirow[t]{2}{*}{29} & Amphitrite & 1 & -2 & $1.28 \times 10^{-11}$ & 23.82 & 1 & -2 & $1.80 \times 10^{-10}$ & 23.82 \\
\hline & & 2 & -2 & $6.15 \times 10^{-12}$ & 1.74 & & & & \\
\hline \multirow[t]{2}{*}{8} & Flora & 3 & -5 & $7.28 \times 10^{-12}$ & 15.54 & & & & \\
\hline & & 2 & -3 & $5.95 \times 10^{-12}$ & 6.90 & & & & \\
\hline \multirow[t]{2}{*}{14} & Irene & 1 & -2 & $5.88 \times 10^{-12}$ & 19.55 & & & & \\
\hline & & 2 & -4 & $5.35 \times 10^{-12}$ & 9.78 & & & & \\
\hline 27 & Euterpe & 1 & -2 & $4.59 \times 10^{-12}$ & 40.81 & & & & \\
\hline
\end{tabular}


S. Mouret et al.: The list of asteroids perturbing the Mars orbit to be seen during future space missions, Online Material $p 6$

Table A.1. continued.

\begin{tabular}{|c|c|c|c|c|c|c|c|c|c|}
\hline \multicolumn{2}{|c|}{ Asteroid } & \multicolumn{4}{|c|}{$\overline{\text { Semi-major axis of Mars }}$} & \multicolumn{4}{|c|}{ Mean longitude of Mars } \\
\hline \multirow[t]{2}{*}{$\mathrm{N}^{\mathrm{o}}$} & \multirow[t]{2}{*}{ name } & \multicolumn{2}{|c|}{$\begin{array}{l}\text { Argument } \\
i \bar{\lambda}_{\mathrm{M}}+j \bar{\lambda}_{\mathrm{c}}\end{array}$} & $\begin{array}{c}\text { Amplitude } \\
c_{i j} \\
{[\mathrm{AU}]}\end{array}$ & $\begin{array}{c}\text { Period } \\
P_{i j} \\
\text { [years] }\end{array}$ & \multicolumn{2}{|c|}{$\begin{array}{l}\text { Argument } \\
i \bar{\lambda}_{\mathrm{M}}+j \bar{\lambda}_{\mathrm{c}}\end{array}$} & $\begin{array}{c}\text { Amplitude } \\
c_{i j} \\
\text { [radian] }\end{array}$ & $\begin{array}{c}\text { Period } \\
P_{i j} \\
\text { [years] }\end{array}$ \\
\hline & & 2 & -4 & $4.17 \times 10^{-12}$ & 20.40 & & & & \\
\hline 51 & Nemausa & 2 & -4 & $7.82 \times 10^{-12}$ & 27.50 & 2 & -4 & $1.03 \times 10^{-10}$ & 27.50 \\
\hline 105 & Artemis & 2 & -4 & $7.74 \times 10^{-12}$ & 33.72 & 2 & -4 & $1.30 \times 10^{-10}$ & 33.72 \\
\hline \multirow[t]{2}{*}{187} & Lamberta & 2 & -5 & $5.85 \times 10^{-12}$ & 22.49 & & & & \\
\hline & & 3 & -7 & $5.15 \times 10^{-12}$ & 22.68 & & & & \\
\hline 192 & Nausikaa & 4 & -8 & $4.76 \times 10^{-12}$ & 48.14 & 4 & -8 & $1.17 \times 10^{-10}$ & 48.14 \\
\hline 313 & Chaldaea & 2 & -4 & $7.15 \times 10^{-12}$ & 33.49 & 2 & -4 & $1.18 \times 10^{-10}$ & 33.49 \\
\hline 356 & Liguria & 2 & -5 & $6.70 \times 10^{-12}$ & 34.78 & 2 & -5 & $1.16 \times 10^{-10}$ & 34.78 \\
\hline \multirow[t]{2}{*}{405} & Thia & 4 & -9 & $4.50 \times 10^{-12}$ & 24.50 & & & & \\
\hline & & 2 & -4 & $4.32 \times 10^{-12}$ & 10.00 & & & & \\
\hline 419 & Aurelia & 4 & -9 & $4.92 \times 10^{-12}$ & 39.28 & 4 & -9 & $9.70 \times 10^{-11}$ & 39.28 \\
\hline \multirow[t]{2}{*}{747} & Winchester & 2 & -5 & $5.09 \times 10^{-12}$ & 9.89 & & & & \\
\hline & & 3 & -8 & $4.90 \times 10^{-12}$ & 18.02 & & & & \\
\hline 16 & Psyche & 2 & -2 & $6.20 \times 10^{-12}$ & 1.51 & & & & \\
\hline 409 & Aspasia & 1 & -2 & $4.88 \times 10^{-12}$ & 20.96 & & & & \\
\hline 451 & Patientia & 1 & -3 & $4.38 \times 10^{-12}$ & 36.43 & & & & \\
\hline 521 & Brixia & 2 & -5 & $4.16 \times 10^{-12}$ & 25.11 & & & & \\
\hline
\end{tabular}

